Review Article

\title{
Preclinical Models for Investigation of Herbal Medicines in Liver Diseases: Update and Perspective
}

\author{
Hor-Yue Tan, ${ }^{1}$ Serban San-Marina, ${ }^{2}$ Ning Wang, ${ }^{1}$ Ming Hong, ${ }^{1}$ Sha Li, ${ }^{1}$ \\ Lei Li, ${ }^{1}$ Fan Cheung, ${ }^{1}$ Xiao-Yan Wen, ${ }^{2}$ and Yibin Feng ${ }^{1}$ \\ ${ }^{1}$ School of Chinese Medicine, Li Ka Shing Faculty of Medicine, The University of Hong Kong, Pokfulam, Hong Kong \\ ${ }^{2} Z$ Zebrafish Centre for Advanced Drug Discovery, Keenan Research Centre for Biomedical Science, Li Ka Shing Knowledge Institute, \\ St. Michael's Hospital and Department of Medicine, University of Toronto, Toronto, ON, Canada
}

Correspondence should be addressed to Xiao-Yan Wen; wenx@smh.ca and Yibin Feng; yfeng@hku.hk

Received 22 October 2015; Revised 23 December 2015; Accepted 30 December 2015

Academic Editor: Yoshiji Ohta

Copyright (C) 2016 Hor-Yue Tan et al. This is an open access article distributed under the Creative Commons Attribution License, which permits unrestricted use, distribution, and reproduction in any medium, provided the original work is properly cited.

\begin{abstract}
Liver disease results from a dynamic pathological process associated with cellular and genetic alterations, which may progress stepwise to liver dysfunction. Commonly, liver disease begins with hepatocyte injury, followed by persistent episodes of cellular regeneration, inflammation, and hepatocyte death that may ultimately lead to nonreversible liver failure. For centuries, herbal remedies have been used for a variety of liver diseases and recent studies have identified the active compounds that may interact with liver disease-associated targets. Further study on the herbal remedies may lead to the formulation of next generation medicines with hepatoprotective, antifibrotic, and anticancer properties. Still, the pharmacological actions of vast majority of herbal remedies remain unknown; thus, extensive preclinical studies are important. In this review, we summarize progress made over the last five years of the most commonly used preclinical models of liver diseases that are used to screen for curative herbal medicines for nonalcoholic fatty liver disease, liver fibrosis/cirrhosis, and liver. We also summarize the proposed mechanisms associated with the observed liver-protective, antifibrotic, and anticancer actions of several promising herbal medicines and discuss the challenges faced in this research field.
\end{abstract}

\section{Introduction}

Hepatic disease refers to a constellation of disorders of the liver that can lead to decompensated liver function. The liver is a very important organ that is mainly responsible for vital functions such as detoxification and glucose and lipid metabolism as well as the synthesis of many key enzymes that regulate these metabolic processes. Acute liver disease is defined as a rapid hepatic dysfunction that occurs in the absence of previous history of chronic liver disease; it is caused, for example, by excessive consumption of antibiotics or acetaminophen. By contrast, chronic liver disease is a longterm dynamic process that involves persistent hepatocytic destruction and regeneration. Major risk factors for chronic liver disease are hepatitis $B$ viral and hepatitis $\mathrm{C}$ viral (HBV and HCV) infection and alcoholic liver-induced injury leading to alcoholic liver disease (ALD) as well as a constellation of metabolic disorders that can lead to nonalcoholic fatty liver disease (NAFLD). Liver exposure to these risk factors gradually results in hepatocytic injury associated with tissue infiltration of inflammatory cells and altered transcriptome in the affected cell populations. As a result, both liver scarring and regeneration are triggered which, if left unchecked, will ultimately progress to profound changes in liver architecture and liver cirrhosis. In addition, patients with cirrhosis have a higher risk of developing hepatocellular carcinoma (HCC) [1].

The incidence of NAFLD is highest among all chronic liver diseases in the United States where it was responsible for $75 \%$ of all cases in 2008 [2]. Globally, the prevalence of NAFLD ranges from 10 to $35 \%$ depending on different diagnostic tools and populations studied. For nonalcoholic induced steatohepatitis (NASH), between 3 and $5 \%$ of the global population is at risk [3]. In clinic, pioglitazone or vitamin $\mathrm{E}$ is only given to patients with advanced stage of NASH who failed lifestyle intervention due to the potential 
risk of the treatment in inducing stroke [4]. Global mortality from liver cirrhosis rose to over 1 million in 2010, accounting for $2 \%$ of all deaths worldwide. Approximately 16 out of every 100,000 people died due to liver cirrhosis worldwide, and the incidence is greater in South and Central Asia as well as Eastern European countries [5]. Liver transplantation remains the only intervention for patients with liver cirrhosis, as alternative drug therapies are not available in the clinic. Antifibrotic therapy is emerging as a possible option as several antifibrotic candidates have been shortlisted preclinically and await further study [6]. Similar to liver cirrhosis, surgical removal and liver transplantation are the most effective treatment for HCC. However, not all patients are suitable for liver surgery as the cancer may have spread and the 5-year survival rate was reported to be about $15 \%$ for patients diagnosed with HCC [7]. There is currently an unfilled medical need to find alternatives to liver transplantation by combating inflammation and the production of reactive oxygen species that are key aspects of chronic liver diseases. In many countries like China, there is a rich history of using herbal medicine to treat liver diseases. Due to the antioxidant and anti-inflammatory nature of these botanicals, their active ingredients could lead to the development of novel hepatoprotective, antifibrotic, and antiliver cancer therapies. To date, plant-based products such as Fuzheng Huayu formula and silymarin have been well documented for use in liver diseases [8]. Fuzheng Huayu formula, an FDA-approved Chinese medicinal formulation, is now undergoing phase IV clinical trial for patients with cirrhosis secondary to HBV infection in China and phase II clinical trial had been completed for chronic hepatitis C patient in US [9]. Although some herbal remedies hold promise for attenuating or reversing the progression of liver diseases, other compounds may be toxic and damage the liver [10]. Therefore, preclinical studies of dose escalation and efficacy testing should be thoroughly conducted in animal models in order to provide a better understanding of safety and efficacy before advancing herbal remedies to clinical studies.

Appropriate in vitro models for NAFLD and liver fibrosis remain to be developed. Furthermore, despite extensive use of immortalized cell lines and primary cultures, effective systems for high throughput drug screening are lacking. In part, this is due to the multifactorial nature of liver disease that is not amenable to investigation through simple in vitro cell models.

In this review, we aim to systematically review the most commonly used animal models that were employed to screen and study the efficacy of herbal medicines for liver diseases. This may serve as a guiding tool for selecting the appropriate liver disease model for herbal medicine screening as well as facilitating further exploration of studied herbal remedies for clinical applications.

\section{Animal Models for NAFLD and NASH}

NAFLD is an idiopathic pathological condition where excessive fat deposition in the liver is caused by factors other than chronic alcohol consumption. If untreated, NAFLD may further progress to nonalcoholic steatohepatitis or NASH and then liver fibrosis/cirrhosis and eventually liver cancer. NAFLD is more prevalent in patients with obesity, diabetes, insulin resistance, and hypertension, which suggests that it is the manifestation of an untreated underlying metabolic dysfunction.

Steatosis or the abnormal accumulation of fats in hepatocytes is thought to be the original disease-causing event leading to further dysfunction through oxidative stress, fatty acid and inflammatory cytokine-mediated liver injury, and apoptosis as well as changed lipid partitioning [11]. Steatosis divides into two general types: macrovesicular and microvesicular, which differ with respect to the number and size of lipid vacuoles and to the position of the nucleus in the cytoplasm. In macrovesicular steatosis, lipid vacuoles are large and the nucleus tends to push aside, while in microvesicular steatosis the nucleus is usually not affected. NAFLD accounts for approximately $5 \%$ of all liver steatosis [12]. However, in NASH, several other pathologies were observed, such as hepatocellular ballooning and intralobular and inflammatory infiltration with immune cells [13].

As mentioned earlier, liver pathology can progress from obesity and insulin resistance to macrovesicular/microvesicular steatosis, hepatocellular ballooning, and intralobular inflammation. At the biochemical level, there is a malfunction in lipid metabolism consisting of increased long chain fatty acid influx and altered fatty acid synthesis as well as decreased triglyceride production. Broadly, two types of animal models for NAFLD/NASH have been described but neither faithfully reflects the human conditions. In one type of the model, the disease is induced by a genetic modification that targets any one of the processes mentioned above while in the other it is caused by altered dietary intake. The $\mathrm{ob} / \mathrm{ob}, \mathrm{db} / \mathrm{db}$, adiponectin null, and KK-Ay models have been routinely employed to study the development of NAFLD. However, these models do not directly progress to steatohepatitis but require additional insults, such as various dietary treatments or the injection of hepatotoxins. On the other hand, diet-based models such as the methionine and choline deficiency (MCD) model or the high fat diet (HFD) model are easier to develop and present some of the histological features of human diseases. However, disease development in these models can vary substantially based on the composition of the diets and the duration of experiments.

The HFD model is most commonly used to explore the effect of herbal medicines on NAFLD and NASH. After 4 months, total fat/body weight was found to be five times higher in experimental HFD mice than in naïve mice. HFD mice had higher total serum cholesterol, triglyceride, and insulin levels as well as impaired glucose tolerance as compared to naïve mice. All these suggest pathological initiation of NAFLD. Administration of rhein, from Rheum palmatum L. after 40 days of HFD, normalized liver fat levels and improved insulin resistance [14]. In another study by Xiao et al. [15], the histopathological modifications of $\mathrm{NASH}$ such as hepatocytic necrosis and infiltration with inflammatory cells were observed after 8 weeks of HFD. Collagen formation detected by Sirius red staining also suggested that the disease was progressing from steatohepatitis 
to hepatic fibrosis. Treatment with Lycium barbarum polysaccharides for 4 weeks reduced insulin resistance and obesity as well as improving the histopathological changes incurred by HFD. Herbal medicines have also shown promising results in the MCD mouse model, where as previously mentioned, methionine and choline are absent from diet [16]. These components are required for beta-oxidation and VLDL synthesis and their dietary suppression leads to fatty acid accumulation and oxidative stress in hepatocytes. A recent study showed that, after eight weeks of MCD, there was observable macrovesicular steatosis, inflammation, and hepatocytic necrosis. Administration of Fuzheng Huayu formula ameliorated these changes through downregulation of CYP2E1 and HO-1, markers of oxidative stress. In addition, TNF- $\alpha$ and IL- 6 were similarly downregulated in this study [17].

Animal models in which liver disease is induced by a combination of selected genetic backgrounds, diets, and the administration of hepatotoxins have also been proposed $[18,19]$. In the study by $\mathrm{Ma}$ et al., ApoE $(-/-)$ mice with HFD showing signs of NAFLD had ameliorated pathological changes after being fed with Huanglian Jiedu extract [20]. One possible explanation for this effect is promotion of phagocytosis by the increased population of M2 macrophages. Similarly, administration of the Japanese herbal medicines Sho-saiko-to and Juzen-taiho-to in MCDfed $\mathrm{db} / \mathrm{db}$ mice for 4 weeks reduced lobular inflammation and liver ballooning [21]. In the above models, SREBP1c, adiponectin, PGC-1 alpha, and FABP were frequently used as biochemical markers to monitor lipid and energy metabolism functions. Overexpression of SREBP-1c induced lipid synthesis and reduced VLDL efflux and lipid oxidation while increasing triglyceride deposition in hepatocytes [22]. Adiponectin is another important cytokine that regulates glucose metabolism and fatty acid breakdown. It is reported that susceptibility for liver fibrosis in adiponectin knockout mice is higher compared to naïve mice [23]. A Japanese herbal medicine, bofutsushosan, ameliorated hepatic steatosis and inflammation through increased plasma adiponectin levels and reduced SREBP-1c expression. Simultaneously, bofutsushosan also enhanced fatty acid oxidation and reduced inflammation through upregulation of $\alpha / \lambda$-PPAR [24]. Similar findings were reported for ping-tang recipe that greatly enhanced $\alpha / \lambda$-PPAR expression while reducing that of the lipogenic genes, SREBP-1c, FAS, and L-FABP [25]. Proposed mechanisms for the observed effects of several herbal medicines against NAFLD and NASH together with the investigated animal models are summarized in Table 1.

\section{Animal Models for Liver Fibrosis and Cirrhosis}

Liver fibrosis is a progressive disease that is caused by viral induced hepatitis, alcoholic induced liver injury, NAFLD/NASH, chronic biliary retention, or parasitic infection induced injury [26]. The underlying pathophysiological process consists of overlapping cycles of wound healing and cell necrosis that ultimately leads to accumulation of extracellular matrix containing collagen and other matrix components [27]. An important event in fibrogenesis is the formation of hepatic myofibroblasts that secrete collagen. If left unchecked, the process results in the complete destruction of liver architecture with hepatic insufficiency that is the marker of a more severe process of cirrhosis. Ultimately, portosystemic shunting leads to liver failure [28]. To date, there is no effective treatment for liver fibrosis or cirrhosis. Whether or not these processes are reversed or arrested in their progression is a matter of current controversy. Yet, animal studies have shown that in some cases experimentally induced liver fibrosis can be reversed using botanical extracts.

Liver fibrogenesis can commonly be induced in animal settings by cholestasis or administration of hepatotoxins. In some studies, fibrosis was induced using longer-term models of alcoholic or nonalcoholic liver injury or by a combination of the two [29]. Recently, models of gene-modified mice were established by knocking down the MDR2 gene or by overexpressing TGF- $\beta 1[30,31]$. The administration of hepatotoxins to induce liver injury in rodents is a model that is commonly used in herbal medicine studies. Liver injury by carbon tetrachloride $\left(\mathrm{CCl}_{4}\right)$ administration is more frequently used than thioacetamide (TAA) or dimethyl/diethyl nitrosamine (DEN) due to short onset of disease development and the direct cytotoxic effect of $\mathrm{CCl}_{4}$ on hepatocytes. $\mathrm{CCl}_{4}$ induced early fibrosis can be detected within two weeks after the first administration, and 5 to 7 weeks are sufficient to detect all the physiological symptoms of liver fibrosis. Continuous administration of $\mathrm{CCl}_{4}$ will eventually lead to liver cirrhosis. The immediate cytotoxic effect of $\mathrm{CCl}_{4}$ on hepatocytes recruits inflammatory cells and induces secretion of proinflammatory cytokines leading to necrosis. Scarring occurs as a result of persistent cycles of cell death and is followed by hepatocytic regeneration/proliferation processes [27]. A study by Zhou et al. [32] showed that 6 weeks of intraperitoneal $\mathrm{CCl}_{4}$ injection 3 times per week resulted in multiple scarring/fibrotic events such as bridged vessels, fibrous septa, and even regenerative nodules. Treatment with Xuefuzhuyu starting at week 4 ameliorated the hepatic stellate cells (HSC) activation and ECM formation and reduced expression of $\alpha$-SMA and collagen I. Another study conducted by Shen et al. [33] also showed that treatment with Diwu Yanggan in a 6-week $\mathrm{CCl}_{4}$ model attenuated epithelial-to-mesenchymal cellular transition, a commonly observed condition in fibrogenesis, through upregulation of E-cadherin and downregulation of vimentin. Compared to $\mathrm{CCl}_{4}$, disease modelling using TAA and DEN (a carcinogen) requires longer exposure time to induce HCC. In all these cases and irrespective of the causative agent, disease development is remarkably similar across the models. For example, intraperitoneal injection of TAA for 6 weeks increased fibrous septa, portal tract, and liver sinusoids as well as $\alpha$-SMA staining of liver cells, the same as in the $\mathrm{CCl}_{4}$ model. In the TAA model, administration of kaerophyllin from Bupleurum scorzonerifolium reversed histopathological changes and further reduced the levels of proinflammatory cytokines TNF- $\alpha$, IL-1 $\beta$, and MCP-1 [34].

It is worth mentioning that Fuzheng Huayu formula, a traditional Chinese medicine that showed antifibrotic effects in clinical practice, also demonstrated significant in vivo 


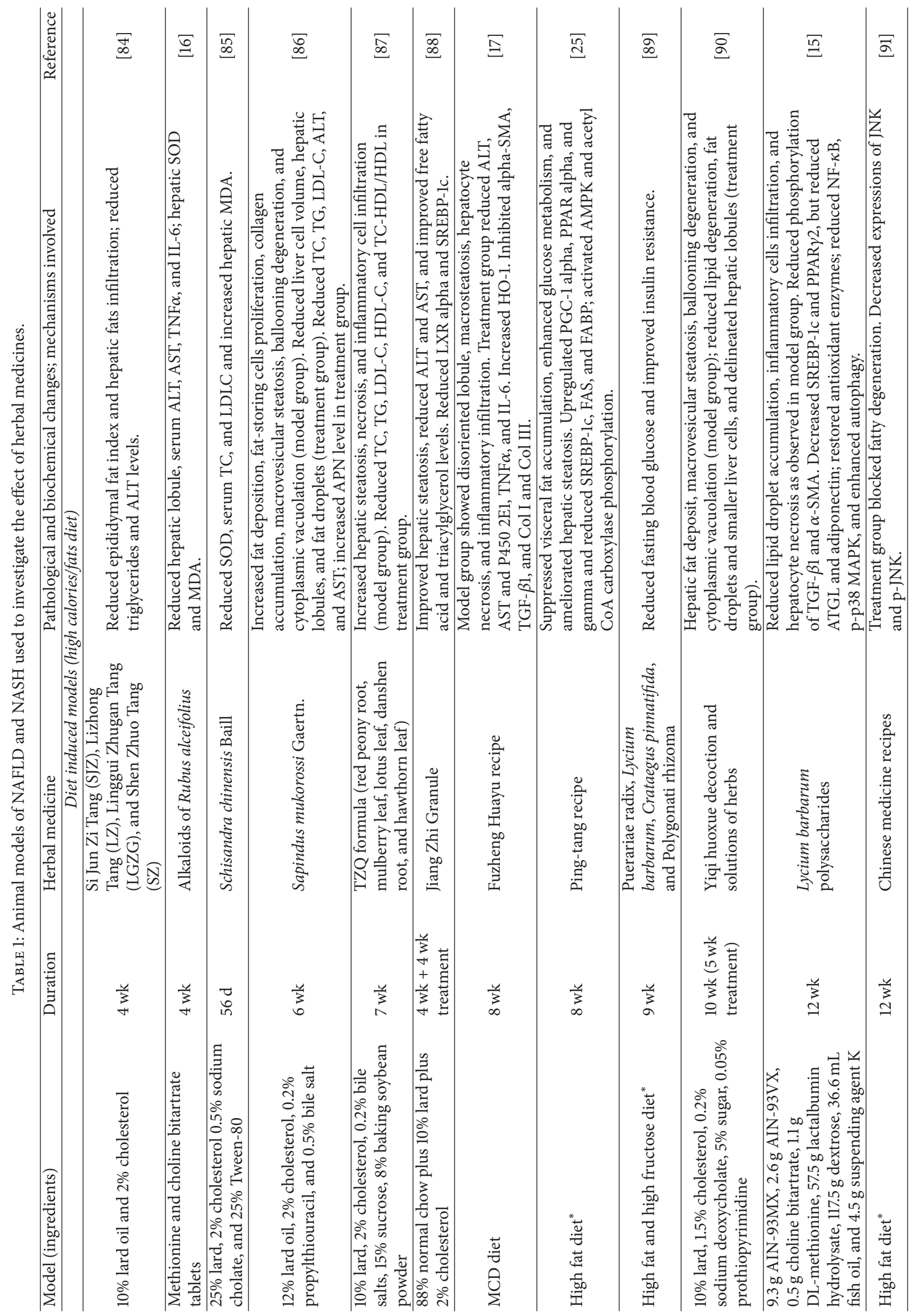




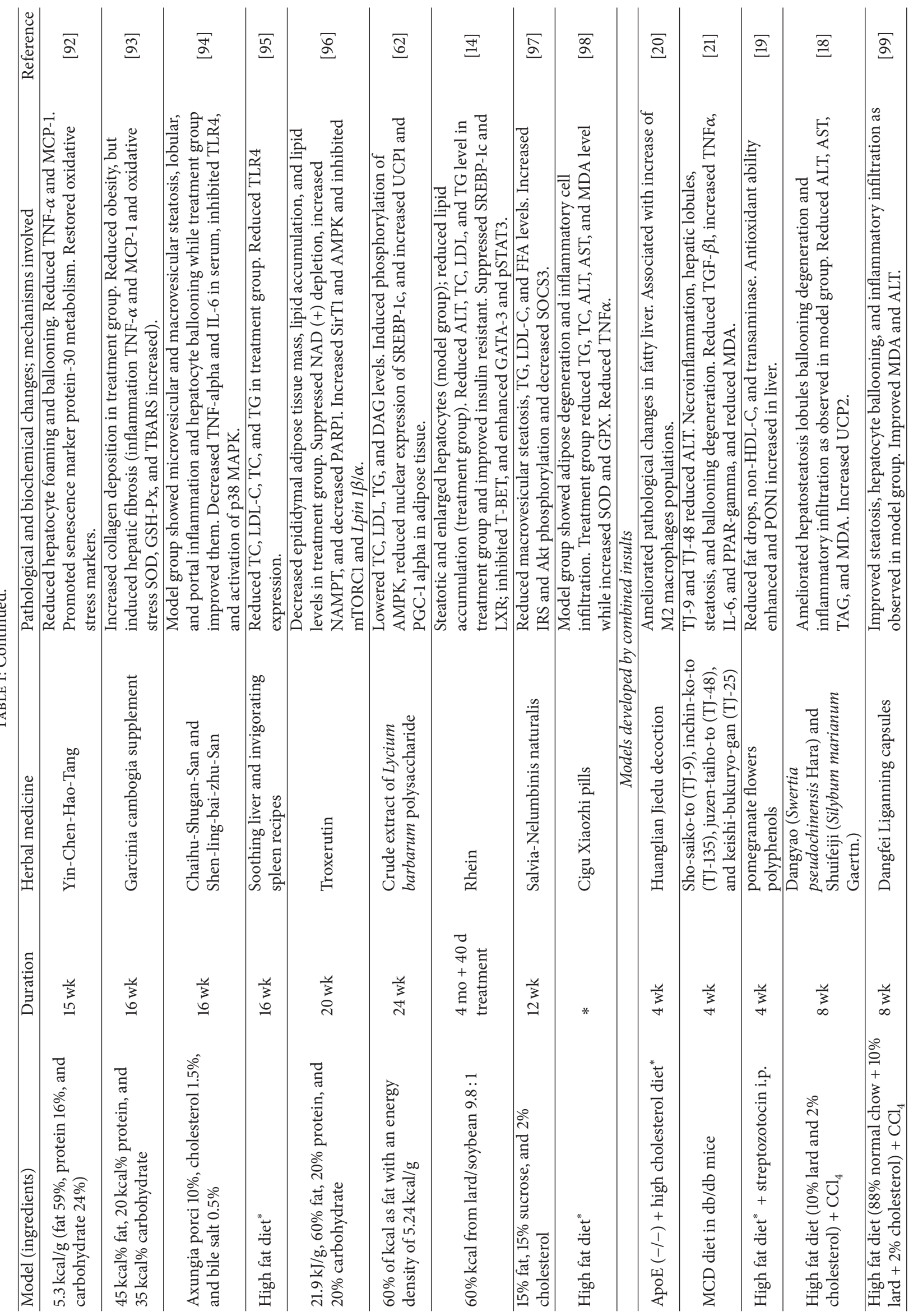




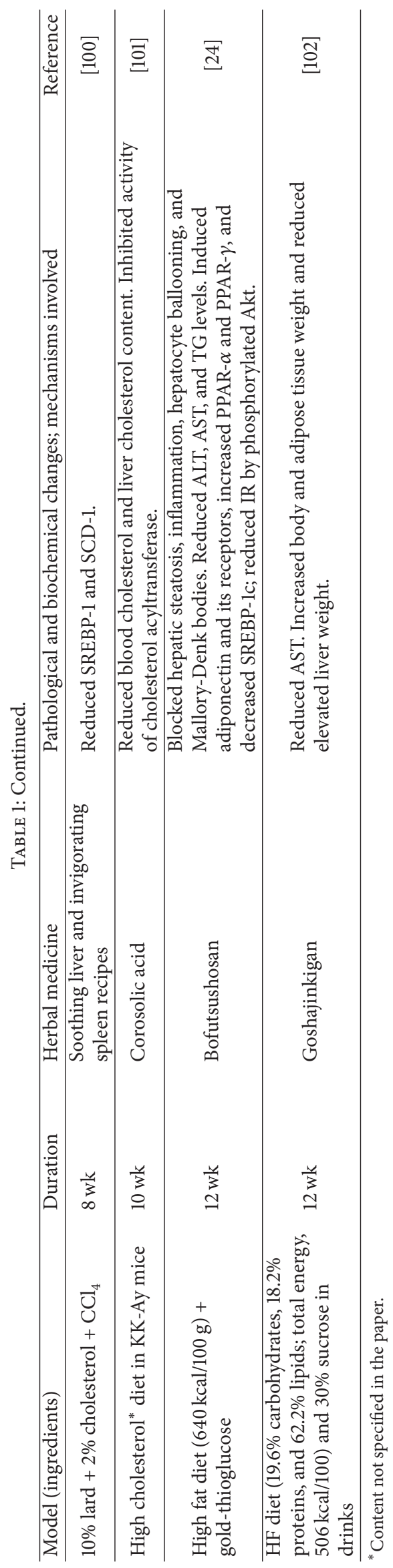


effect in DEN and $\mathrm{CCl}_{4}$ models [35-38]. Currently, the Fuzheng Huayu formula is in a phase IV multicenter clinical trial for HBV induced liver cirrhosis [39]. In DMN-induced mice, administration of Fuzheng Huayu formula reduced inflammatory cell infiltration and collagen accumulation and lowered $\alpha$-SMA expression. The antifibrotic effect of the extract is believed to downregulate TGF- $\beta 1$ and $\mathrm{p}-\mathrm{Smad} 2 / 3$ in injured tissue [35] as well as attenuating apoptosis via TNF $\alpha$ blockade [36]. Our research group has extensively studied the Coptidis rhizoma aqueous extract (CRAE), a traditional Chinese medicine used in clinical practice for liver disease. Simultaneous administration of CRAE and $\mathrm{CCl}_{4}$ for 8 weeks alleviated the formation of fibrous septa, pseudo lobes, and collagen deposition. The effect is comparable to that of bear bile, a medicine traditionally used for liver disease, which is also effective in $\mathrm{CCl}_{4}$ induced, cholestatic, and alcohol fed murine models [40]. The protective effect of Coptidis rhizoma extracts may be secondary to ameliorating oxidative stress and decreasing apoptosis [41]. Proposed mechanisms of action of herbal medicines in liver fibrosis/cirrhosis and the models used to test them are summarized in Table 2.

Liver fibrogenesis results from excessive deposition of extracellular matrix and is part of a wound healing process triggered by activation of hepatic stellate cells. The process is accompanied by cell necrosis, apoptosis, and inflammation [27]. TGF- $\beta 1$ plays an important role in liver injury, by regulating the inflammation process, hepatocyte apoptosis, and the transformation of hepatic stellate cells to myofibroblasts. Transformed myofibroblasts secrete matrix metalloproteinases (MMPs) that degrade the extracellular matrix of normal cells and further promote deposition of fibrillar collagens [26]. Due to the large number of myofibroblasts and collagen deposited in fibrotic regions, the hepatic expressions of $\alpha$-SMA and type I/II collagen also increase significantly. Therefore, these biochemical markers as well as the inflammatory factors MCP-1 and TNF $\alpha$ frequently used to evaluate the effect of herbal medicines in experimental liver fibrosis models.

Cholestatic models where bile efflux is impeded through induction of obstructive bile duct injury are also frequently used to study the effect of herbal medicines on biliary fibrosis. After surgical bile duct ligation, animals develop periportal hepatocyte necrosis, liver failure, and fibrosis within one week. Inflammatory cell infiltration, hepatocyte apoptosis, and collagen deposition are observed in 4 weeks after bile duct ligation. This murine surgical model is often used because it is fast and reproducible, even though it can result in high mortality within a few weeks, an outcome that does not mirror the slow progression of the disease in humans [29]. In animals, undergoing bile duct ligation with administration of huangqi extract restored expression of TGF- $\beta 1, \alpha$-SMA, albumin, and CK7 markers [42]. Proposed mechanisms for the actions of herbal medicines on biliary fibrosis and models used to study the effects are summarized in Table 3.

\section{Animal Models for HCC}

Exposure to a variety of agents can lead to malignant transformation of hepatocytes, a multistep process characterized by recurrent genetic modifications. HCC is the most common type of primary hepatic cancer. Its development is related to several risk factors such as HBV and HCV infection, alcoholic liver disease, and NAFLD as well as exposure to environmental toxins such as aflatoxins and diethyl nitrosamine [43]. The most effective treatment for HCC is surgical removal of the affected liver tissue followed by liver transplantation. Because HCC is most commonly diagnosed in late stages where extrahepatic metastasis is often present, early therapeutic interventions have not been explored at length.

Not surprisingly, some of these disease-causing agents mentioned above have been used to establish animal models for HCC. There are HBV/HCV transgenic mice models as well as models in which genetic alterations are induced through either knocking out of tumour suppressor genes or overexpressing c-myc or TGF- $\alpha$ protooncogenes. These models retain some features of the multistep processes of HCC development in humans and are frequently used to delineate the role of specific genes in hepatocarcinogenesis as well as studying the outcome of host-tumour interactions on disease progression [44]. Choedon et al. [45] used a HBx15-c$m y c$ mouse model for HCC, in which a truncated HBx allele is overexpressed together with c-myc, to show that Thapring, a traditional Tibetan medicine, restores liver function after 10 months of treatment with concomitant reduction in serum of SOD and VEGF levels. The significant antitumour effect of Thapring is presumably linked to increased expression of p21 Waf1 and the apoptosis [45].

Xenograft models in which tumour cell suspensions are implanted subcutaneously in mice have been extensively used to monitor tumour growth and effectiveness of new therapies. This is often the first-line model for anticancer agent screening in vivo. Recent study by the National Cancer Institute [46] showed up to $45 \%$ of anticancer agents confirmed to be clinically effective demonstrated cytotoxic effects in xenograft models of HCC. The H22 xenograft model that is established through injection with $\mathrm{H} 22$ cell lines is particularly attractive among other models, due to the relatively short induction time to develop solid tumours (approximately 2 weeks). Both subcutaneous and intraperitoneal injections can induce solid tumour formation [47] although the details for this cell line are not well described in the literature. Administration of Eupolyphaga sinensis inhibited H22 tumour growth by promoting secretion of TNF- $\alpha$ and IFN- $\gamma$ as well as inducing apoptosis via increased $\mathrm{Bax} / \mathrm{Bcl}-2$ ratio and caspase-3 production [48]. Furthermore, coadministration of chemotherapeutic agents together with herbal medicines significantly increased the cytotoxic effects. Cao and colleagues [49] showed that coadministration of Fuzheng-Yiliu granules with low dose 5-fluorouracil potentiated antitumour activity and restored white blood cell count. Similarly, combination treatment of Chaiqiyigan granula with taxol had a stronger antitumour effect than that of taxol alone [50]. Using xenograft models, our research group has shown a potent antitumour effect of Coptidis rhizoma aqueous extract. The effect was associated with decreased levels of markers for cell proliferation and vessel density such as Ki67 and CD31 $[51,52]$. 


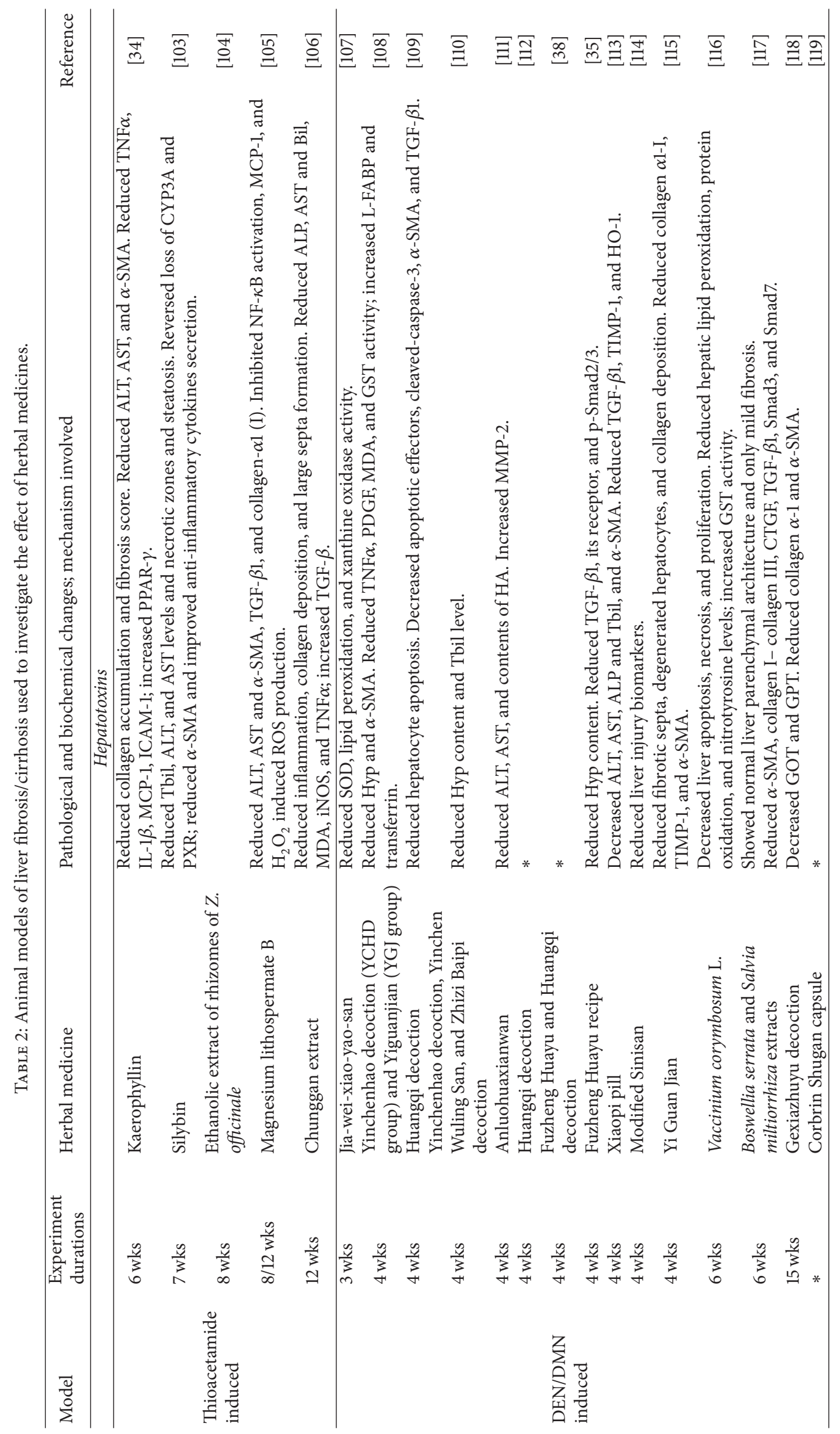




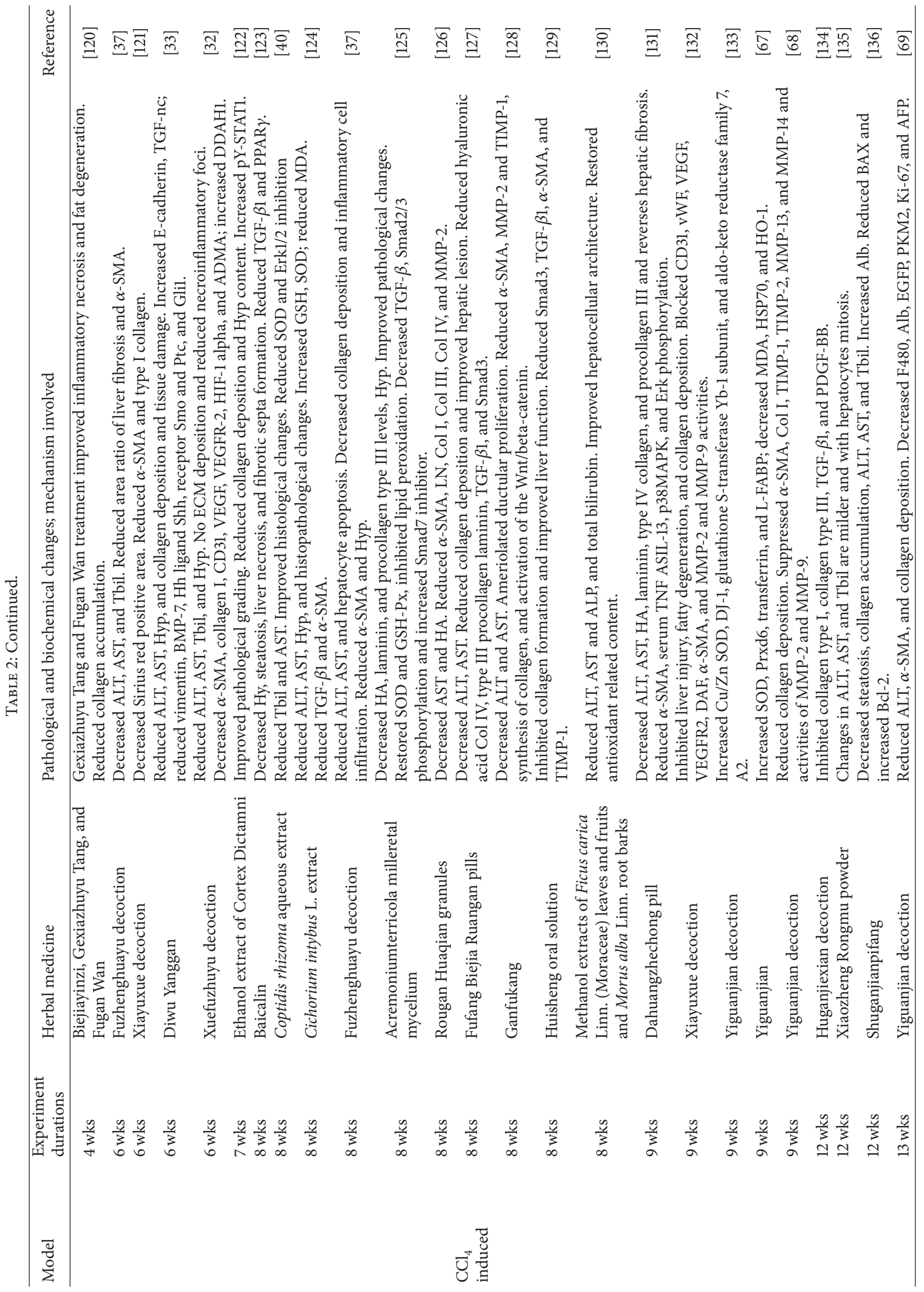




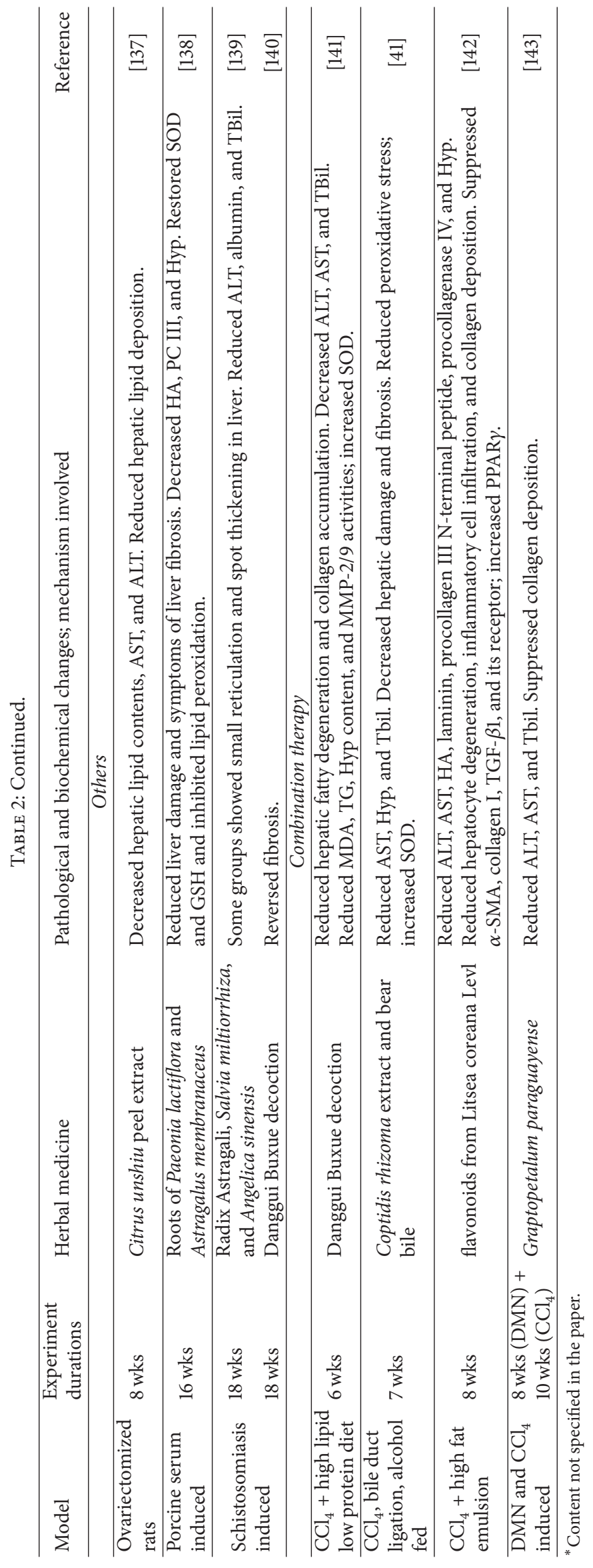


TABLE 3: Animal models of biliary fibrosis used to investigate the effect of herbal medicines.

\begin{tabular}{|c|c|c|c|c|}
\hline Model & $\begin{array}{l}\text { Experiment } \\
\text { durations }\end{array}$ & Herbal medicine & Pathological and biochemical changes; mechanism involved & Reference \\
\hline \multirow{7}{*}{$\begin{array}{l}\text { Bile duct } \\
\text { ligation }\end{array}$} & 3 days & $\begin{array}{l}\text { Aqueous extract from } \\
\text { the root of Platycodon } \\
\text { grandiflorum }\end{array}$ & $\begin{array}{l}\text { Blocked ALT and AST. Restored antioxidant enzymes. High dose } \\
\text { showed lesser hepatocyte necrosis and inflammatory cell } \\
\text { infiltration. }\end{array}$ & {$[144]$} \\
\hline & 2 weeks & Yang-Gan-wan & Reduced $\alpha 1$ (I) procollagen and $\alpha$-SMA. & {$[145]$} \\
\hline & 2 weeks & Artemisia capillaris & $\begin{array}{l}\text { Reduced cholestatic markers and Hyp. Blocked liver injury and } \\
\text { collagen deposition. Reduced } \alpha \text {-SMA, PDGF, and TGF- } \beta \text {. }\end{array}$ & {$[146]$} \\
\hline & 28 days & Green tea polyphenol & $\begin{array}{l}\text { Reduced portosystemic shunting, fibrosis, intrahepatic } \\
\text { angiogenesis, and mesenteric window vascular density. Decreased } \\
\text { HIF-1 } \alpha \text {, VEGF, and phospho-Akt. }\end{array}$ & [147] \\
\hline & 4 weeks & Huangqi decoction & Reduced fibrosis degree. Increased Hyp content, CK7, and $\alpha$-SMA. & {$[148]$} \\
\hline & 4 weeks & Huangqi decoction & $\begin{array}{l}\text { Blocked collagen deposition. Reduced ALT, Tbil, and Hyp. } \\
\text { Inhibited TGF- } \beta 1 \text {, its receptors, SMAD3, and pERK1/2. }\end{array}$ & {$[42]$} \\
\hline & 7 weeks & Inchinko-to & Decreased ALT and AST. Reduced TGF- $\beta 1$ and $\alpha$-SMA. & [149] \\
\hline
\end{tabular}

Orthotopic models in which tumour cells are implanted directly into the organ of interest are considered more clinically relevant and better predictive models for drug efficacy because the emerging liver tumours better reflect the niche microenvironment. Although this model is more technically demanding, it recapitulates key events of the human disease, such as displacement of the normal cell population by tumour formation as well as the production of circulating metastatic tumour cells. Wang and colleagues [53] implanted HepG2 cells expressing red fluorescent protein into mouse livers and monitored tumour growth and metastasis by fluorescence imaging. Metastatic spread to pancreas and mediastinal lymph nodes was observed after 25 days of post-HepG2 implantation. Early treatment with Celastrus orbiculatus effectively blocked tumour growth. Similar to observations made in humans regarding the administration of chemotherapeutics in later stages of liver disease, the effect of Celastrus orbiculatus became less significant when the treatment was started after the tumours formed. In a previous study, we also implanted luciferase-tagged MHCC97L tumours into BalB/c nude mice in order to observe the effect of berberine, the major ingredient of Coptidis rhizome. The treatment effectively suppressed tumour growth and lung metastasis [54]. Some of the antitumour mechanisms of herbal medicines in liver cancer and the models used are summarized in Table 4.

\section{Animal Models for Acute Liver Injury}

There is a growing number of studies describing the effect of herbal medicines in acute liver failure. Acute liver failure is defined as a severe impairment of liver function within short duration and without a history of preexisting liver disease. Acute injury leading to liver failure may be less frequent in the clinic than other forms of liver failure and yet it is life-threatening [55]. In humans, drug-induced liver injury (e.g., from high doses of acetaminophen, antibiotics, or antituberculosis drugs) is the major cause of acute liver failure. Other leading causes are viral infections and accidental toxicity such as excessive alcohol consumption or mushroom poisoning as well as those caused by ischemic or metabolic disorders. Much current herbal medicine research focused on the hepatoprotective actions of herbal medicines in acute liver injury models induced by hepatotoxins, chemicals, or drugs. A list of hepatoprotective herbal medicines and related animal models is shown in Table 5. Most of these disease models are of short duration and include studies of acute biochemical parameters of liver injury such as liver enzyme levels (i.e., ALT and AST) and inflammatory markers as well as markers of organ health such as circulating albumin and total bilirubin. The histological changes for acute liver injury model are not as significant as the longerterm model. Yet, it could be identified through the induction of vacuole formation, infiltration of inflammatory cells, and hepatocytes necrosis and apoptosis. In many instances, the toxicity model is established either concurrently or following the administration of herbal medicines in order to determine an extract's hepatoprotective effect. For example, after 15 days of treatment with an aqueous licorice extract, mice were given an acute oral dose of $\mathrm{CCl}_{4}$ and sacrificed after 8 hours. Licorice-pretreated mice had significantly lower circulating liver enzymes and increased antioxidant enzymes in the liver, such as superoxide dismutase (SOD), catalase (CAT), glutathione peroxidase (GSH-Px), glutathione reductase (GR), and glutathione S-transferase (GST), indicating a hepatotoxic preventive effect from the licorice extract [56]. In acetaminophen-induced hepatotoxicity, coadministration of Tournefortia sarmentosa reduced CAT, SOD, and GPx antioxidant enzyme levels indicating less liver stress and decreased levels of inflammatory factors (TNF- $\alpha$, IL-1 $\beta$, and IL-6) [57]. Most hepatoprotective herbal medicines reverse liver injury through attenuation of injury-associated oxidative stress and inflammation resulting in lower levels of circulating and total bilirubin. Because at the moment liver transplantation is the only cure for acute liver failure, there is an urgent need to further explore the hepatoprotective effect of herbal medicines. 


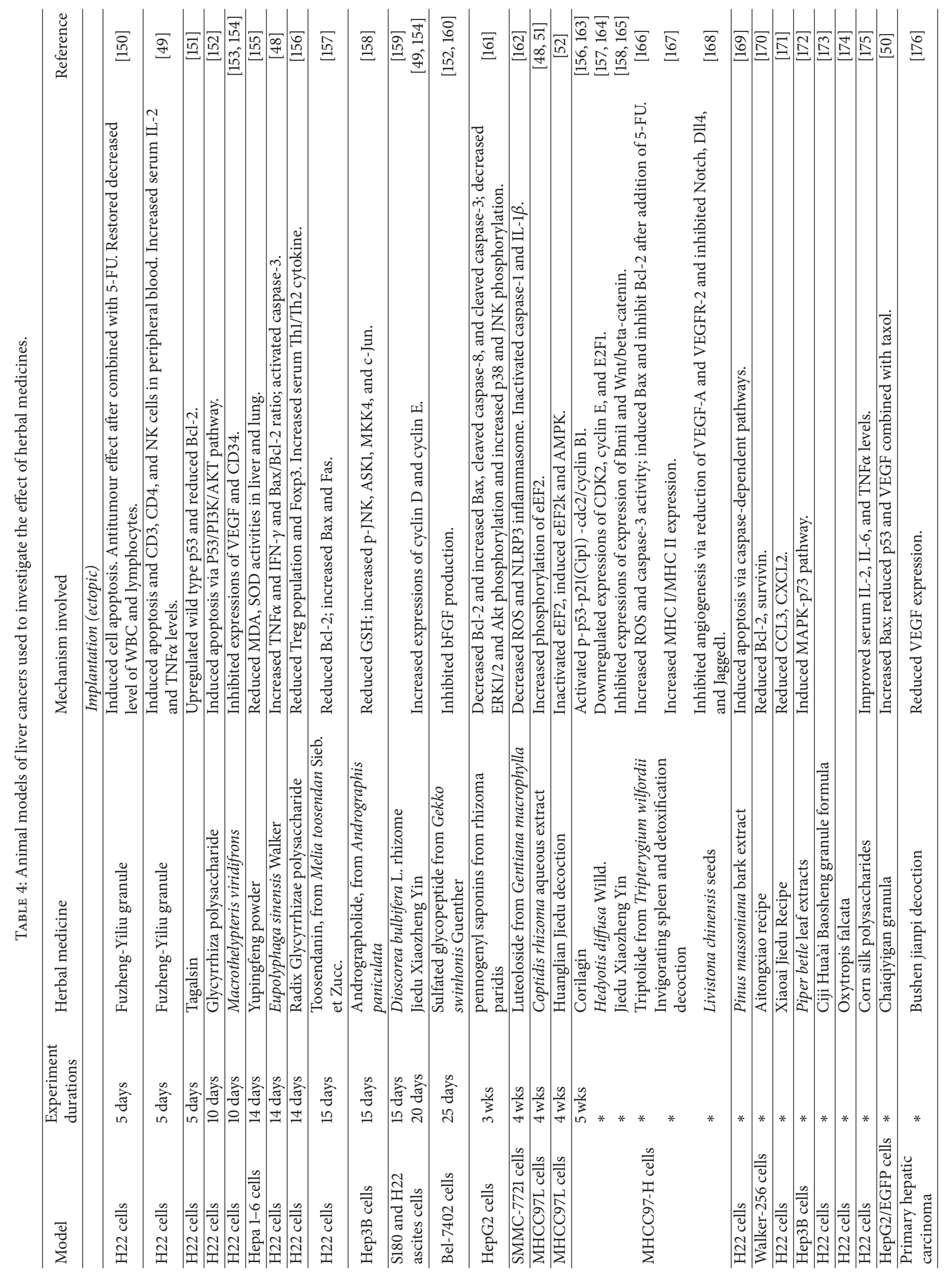




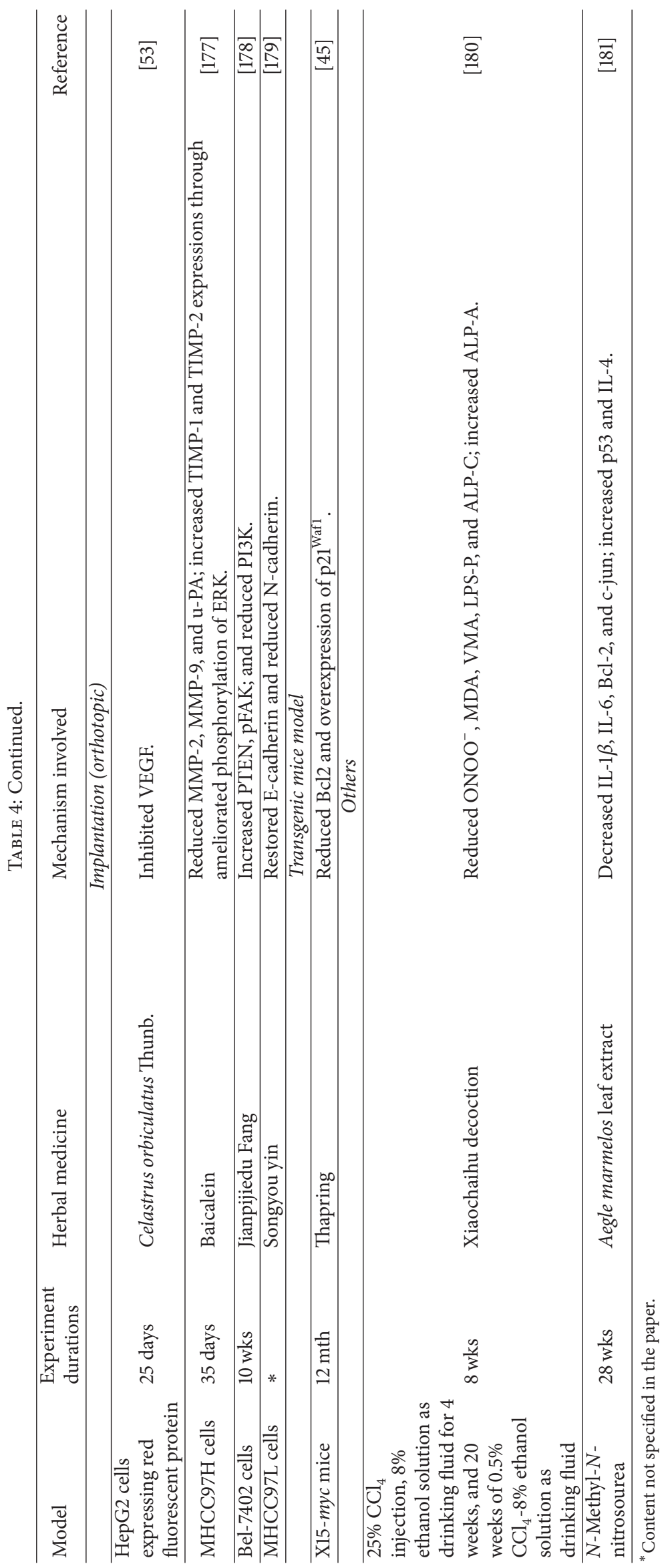




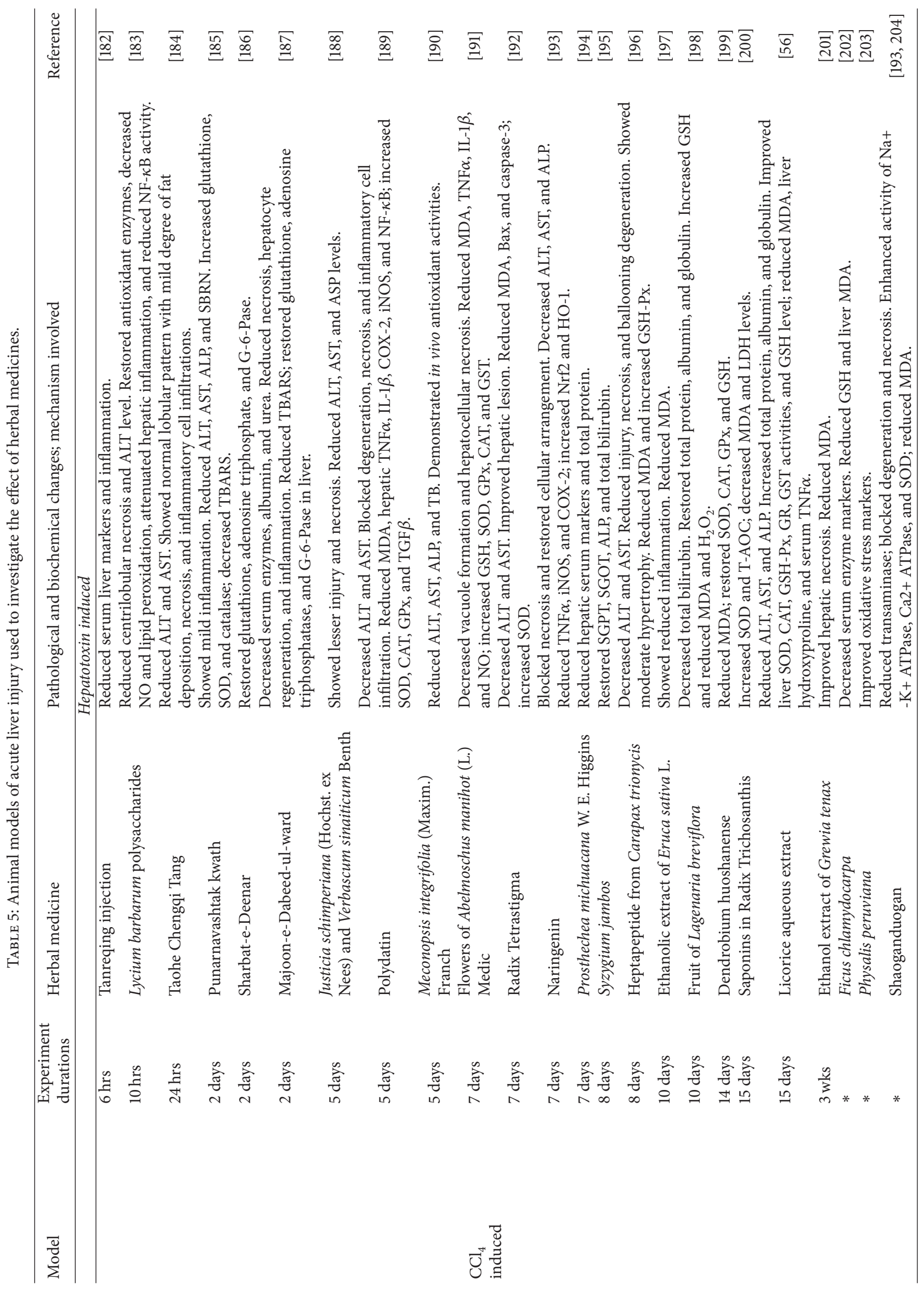




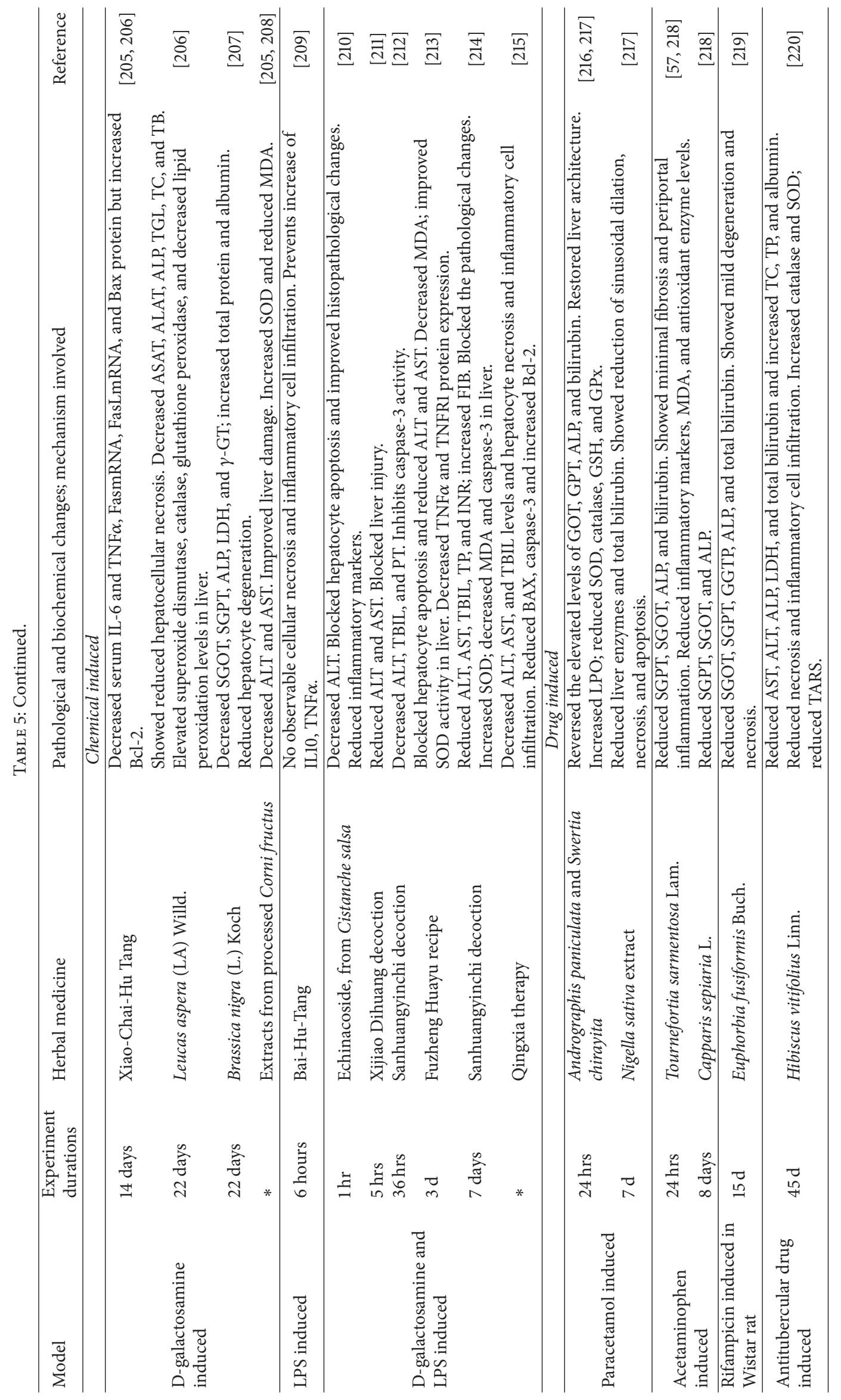




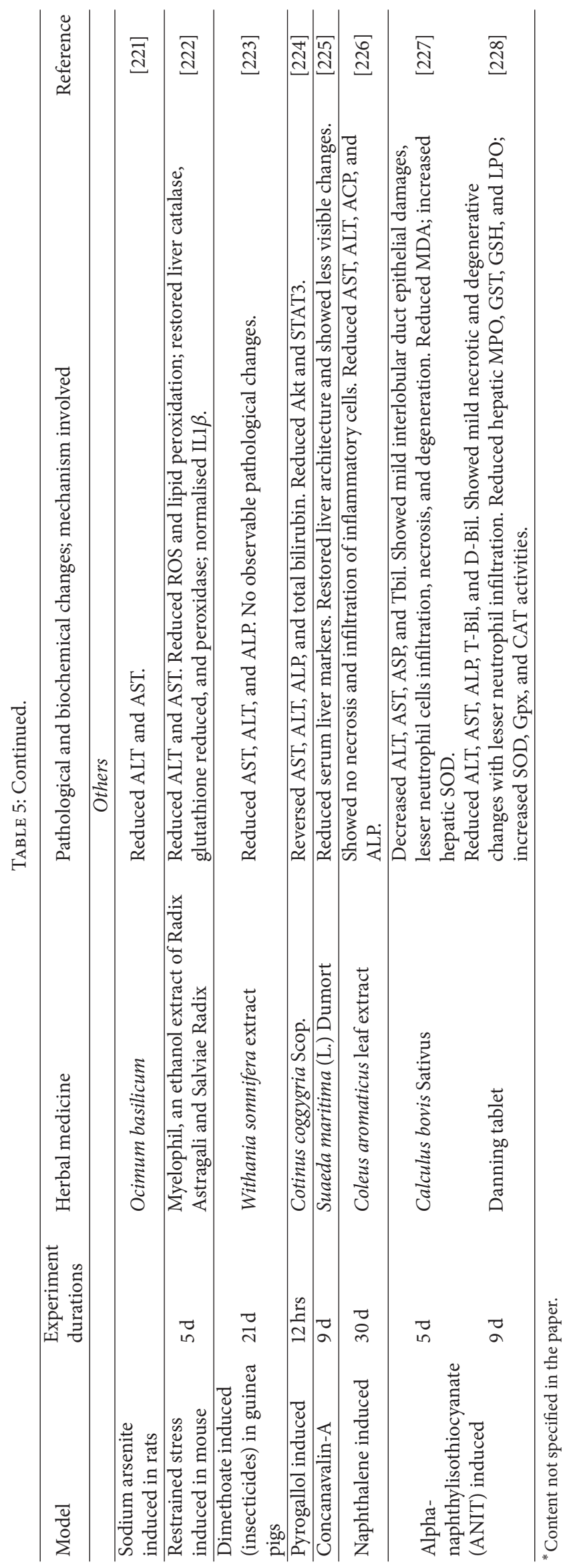




\section{Discussion}

6.1. Mechanisms Associated with Cytoprotective Effects of Herbal Medicines in Liver Diseases. Oxidative stress is one of the key drivers of liver disease pathogenesis. Damage by oxidative stress results when the natural balance between production and breakdown of reactive oxygen species (ROS) is disturbed. In NAFLD, beta-oxidation in mitochondria leads to disturbances in electron transport reactions and elevates ROS production [58]. ROS has been implicated in altered hepatocyte ploidy as well as the initiation of genomic changes that may further promote progression to HCC. In keeping with the reported deleterious effects of ROS on liver function, antioxidants contained in herbal remedies were shown to restore normal hepatocyte ploidy in NAFLD [59]. In the HFD induced NAFLD model, mice fed with excessive fat showed accelerated mitochondrial and peroxisomal fatty acids $\beta$-oxidation as well as increased microsomal fatty acid $\omega$-oxidation [60]. Furthermore, ROS has also been implicated in the $\mathrm{CCl}_{4}$ model of liver fibrosis. $\mathrm{CCl}_{3}$ radicals resulting from administration of $\mathrm{CCl}_{4}$ interact with oxygen to produce highly reactive peroxy radicals that promote lipid peroxidation through removing hydrogen groups from unsaturated fatty acids [61]. One way that herbal medicine contributes to the amelioration of liver diseases is by improving antioxidant activity through chemical reduction of malondialdehyde (MDA) or by boosting glutathione S-transferase (GST) activity. High concentrations of the antioxidants, terpenes, and flavonoids in herbal medicines are likely responsible for the protective effect. In addition, herbal medicines increase the activity of many liver enzymes involved in ROS scavenging such as catalase, superoxide dismutase (SOD), and glutathione peroxide (GPx) as well as reducing ROS production via promoting formation of GSH, the antioxidant. Another instance of liver protection is associated with upregulation of UCP, a mitochondrial carrier $[18,62]$ involved in ROS metabolism.

Apart from oxidative stress, inflammation is another principal driver of liver disease. Persistent inflammation can be triggered through activation of resident macrophages and infiltration with immune cells from the blood stream following injury as well as the interaction of immune cells with surrounding liver tissues [27]. All these will lead to excessive secretion of proinflammatory cytokines TNF$\alpha$, IL- 6 , and IL- $1 \beta$ and further contribute to cell death. Furthermore, TGF- $\beta$ secretion by activated monocytes was shown to stimulate hepatic stellate cells to increase collagen production [63]. These observations underscore the important role of inflammation-related host-cell interactions in liver disease. Many herbal medicines possess potent antiinflammatory activities that attenuate cytokine or chemokine production. Although there are few studies reported on how herbal remedies regulate immune cells or hepatocytes to attenuate inflammation, several protein targets such as NF$\kappa \mathrm{B}, \mathrm{STAT} 3$, and AMPK have been suggested. By inhibiting these pathways, some herbal remedies effectively protect the liver against inflammation-induced damage.
6.2. In Vitro Models for Liver Diseases. To date, herbal medicine research in liver diseases, particularly NAFLD/ $\mathrm{NASH}$ and fibrosis, rarely employed in vitro cell models because of their limitation in mimicking clinical pathogenesis. Although immortalized cell lines and primary cultures have been used for herbal medicine studies, interactions between different cell types and the influence of extracellular matrix as well as other aspects in the niche microenvironment, which are significant disease-contributing factors in humans, cannot be replicated in cell culture models. Using nonalcoholic fatty liver disease as an example, interactions between adipocytes and hepatocytes regulate secretion of free fatty acids that further promotes the transition of hepatocytes and surrounding nonparenchymal cells towards the disease state. Thus, many factors need to be considered regarding whether a cell model of the liver disease is to produce valuable translational outcome. Still, due to the simplicity of studying molecular mechanisms of disease and the ease of obtaining drug leads, a lot of efforts have been directed at establishing or optimizing in vitro cell models for high throughput drug screening. Xu et al. [64] established a TGF- $\beta 1$ fibrogenesis two-cell based model that allows efficient quantification of the effects of antifibrotic drugs on $2 \mathrm{D}$ matrix accumulation and $3 \mathrm{D}$ nodule formation. The model has been employed in kidney fibroblasts for the screening of Chinese medicine compounds and herb extracts for inflammation independent antifibrotic activity [65]. Another model established by Chen et al. [66] is the "scar-in-a-jar" model that improves current fibroplasia models by incorporating in situ optical bioimaging for cell and collagen quantitation. Yet, neither of these two models has been used at length to screen for antifibrotic herbal remedies. A substantial leap in our ability to investigate the use of herbal medicines in liver diseases is expected to occur following the establishment of new models or improvement of existing ones.

6.3. Future Perspectives. Due to the limitation of cell models to provide translatable solutions for clinical applications, animal models remain important for translating a promising herbal compound into the clinic. The preferred protocol is to firstly establish a genetically modified or diet fed mouse model that exhibits some key aspect of the human pathogenesis. In humans, liver disease pathogenesis requires years of genetic evolution and cellular dysfunction in which processes such as cross talk between parenchymal and nonparenchymal liver cells as well as involvement of immune cells occur. Thus, the effects of herbal medicines on these cellular processes need to be delineated in order to provide a better understanding of the processes involved and to facilitate better translational context for human studies.

Single animal model and short duration studies that aim to establish the effectiveness of any herbal medicine are relatively unpersuasive. Typically, such studies use a narrow spectrum of outcomes with limited measurement criteria that may be poorly translatable to human studies. Clearly, even in complex models, the complete pathogenesis of a specific liver disease is rarely recapitulated and therefore more than one animal model is needed to validate the effectiveness of an herbal remedy. Several herbal medicines mentioned above 
show a profound reversal of liver disease markers and need to be studied further. For example, the potent antifibrotic effect of Yi Guan Jian extract that has been extensively studied in the $\mathrm{CCl}_{4}$ model is attributed to the blockade of fibrogenesis due to bone marrow derived fibrogenic cells in the liver [67-69]. However, this effect is oxidative stress-dependent and can only be partially reproduced by administration of $\mathrm{CCl}_{4}$ that severely damages the liver and does not reflect the conditions present in the human disease. Further studies using different rodent models should be implemented to eliminate the possibility that the therapeutic effect of this herbal remedy is due to model-specific bias.

Although preclinical studies have mostly used mouse models, alternative models based on zebrafish are now emerging. With a sequenced genome, the zebrafish has recently emerged as a robust vertebrate model for a variety of human diseases, including the liver diseases [70, 71]. Zebrafish is amenable to unparalleled ease of embryonic manipulation and adaptability for high throughput screens. Furthermore, the physiological similarities between zebrafish and the humans provide a strong rationale for direct drug discovery on zebrafish embryos with translational potential $[72,73]$. Zebrafish studies further benefit from a vast array of newly developed research tools such as genome-wide ENU mutagenesis, transgenesis, and genome editing/gene knockout by ZFN, TALENs, and CRISPR. These tools are readily available to create gene-modified models of liver diseases that can be applied to large scale screens of herbal compounds/extract as well as mechanistic studies of disease progression [74].

Recently, zebrafish has been actively explored as models for NAFLD and/or steatosis using dietary addition of fructose [75] or by introducing a slc7a3a mutation to knockout genes involved in NO-AMPK-PPAR- $\gamma$ signalling pathway [76]. ENU-mutagenized zebrafish larvae have also been used for genetic screens aimed at identifying novel genes that contribute to NAFLD/NASH phenotype [77]. Studies towards the development of zebrafish hepatic fibrosis model showed that administration of diethylnitrosamine resulted in $80 \%$ of treated zebrafish developing liver fibrosis after 6 weeks of treatment [78]. In an effort to build spontaneous hepatic cancer models in zebrafish, either constitutively or by using chemical inducers of liver-specific promoters, the Gong team has achieved targeted liver overexpression of a number of oncogenes such as Kras (V12) and Myc [79-82]. The Stainier lab has also developed a hepatocyte-specific activated $\beta$ catenin model in which $78 \%$ of transgenic zebrafish developed hepatocellular carcinoma by 6 months of age [83]. It is anticipated that these unique genetic zebrafish liver disease models and others will lead to further mechanistic studies as well as large-scale screens of herbal medicines in the near future.

\section{Conclusion}

Herbal medicines contain a wealth of empirical pharmacological outcomes distilled over centuries of practice but more research efforts should be tried in identifying the active medicinal ingredients. This rediscovery or modernization of traditional Chinese medicine holds great promise for new active compounds with cytoprotective, disease-arresting, and curative properties. There are still many challenges to establish relevant animal models for studying the efficacy of the promising compounds outlined in this review. The process of animal modelling is crucial to generate valuable translatable outcomes. Currently, no single model exists that completely recapitulates the entire pathological progression of NAFLD, $\mathrm{NASH}$, cirrhosis, HCC, or acute liver injury. Therefore, data obtained from one model needs to be validated and studied further in other models. It is anticipated that, by employing new genome editing technologies such as CRISPR, more faithful animal models of liver disease will emerge that will push the current boundaries of herbal medicine research. While rodent models remain paramount for the study of drug efficacy, mechanism of action, and toxicity, new emerging zebrafish models assisted by a host of recent technologies hold great promises for high throughput screens of new bioactive compounds in herbal medicines.

\section{Conflict of Interests}

The authors declare no conflict of interests.

\section{Authors' Contribution}

Hor-Yue Tan and Serban San-Marina drafted the paper. All authors revised and commented on the paper and discussed the paper. Xiao-Yan Wen and Yibin Feng conceived, designed, revised, and finalized the paper.

\section{Acknowledgments}

This research was partially supported by the Research Council of the University of Hong Kong (Project codes: 104002889 and 104003422; Yibin Feng), Wong's Donation (Project code: 200006276; Yibin Feng), the donation of Gaia Family Trust, New Zealand (Project code: 200007008; Yibin Feng), Canada Foundation for Innovation (Xiao-Yan Wen), and Brain Canada Foundation (Xiao-Yan Wen).

\section{References}

[1] Y. Liu, C. Meyer, C. Xu et al., "Animal models of chronic liver diseases," The American Journal of Physiology-Gastrointestinal and Liver Physiology, vol. 304, no. 5, pp. G449-G468, 2013.

[2] Z. M. Younossi, M. Stepanova, M. Afendy et al., "Changes in the prevalence of the most common causes of chronic liver diseases in the United States from 1988 to 2008," Clinical Gastroenterology and Hepatology, vol. 9, no. 6, pp. 524.e1-530.e1, 2011.

[3] G. Vernon, A. Baranova, and Z. M. Younossi, "Systematic review: the epidemiology and natural history of non-alcoholic fatty liver disease and non-alcoholic steatohepatitis in adults," Alimentary Pharmacology and Therapeutics, vol. 34, no. 3, pp. 274-285, 2011.

[4] J. K. Dyson, Q. M. Anstee, and S. McPherson, "Non-alcoholic fatty liver disease: a practical approach to treatment," Frontline Gastroenterology, vol. 5, no. 4, pp. 277-286, 2014. 
[5] A. A. Mokdad, A. D. Lopez, S. Shahraz et al., "Liver cirrhosis mortality in 187 countries between 1980 and 2010: a systematic analysis," BMC Medicine, vol. 12, article 145, 2014.

[6] D. Schuppan and N. H. Afdhal, "Liver cirrhosis," The Lancet, vol. 371, no. 9615, pp. 838-851, 2008.

[7] A. C. Society, "Survival rates for liver cancer," 2015, http://www .cancer.org/cancer/livercancer/detailedguide/liver-cancer-survival-rates.

[8] M. W. Fried, V. J. Navarro, N. Afdhal et al., "Effect of silymarin (milk thistle) on liver disease in patients with chronic hepatitis $\mathrm{C}$ unsuccessfully treated with interferon therapy: a randomized controlled trial," The Journal of the American Medical Association, vol. 308, no. 3, pp. 274-282, 2012.

[9] N.i.o. Health, "Treatment of Liver Cirrhosis Due to Hepatitis B Virus With Fuzheng Huayu and Entecavir," 2014, https:// clinicaltrials.gov/ct2/show/study/NCT02241590.

[10] Q. Xu, Y. Feng, P. Duez, B. M. Hendry, and P. J. Hylands, “The hunt for antifibrotic and profibrotic botanicals," Science, vol. 346, no. 6216, supplement, pp. S19-S20, 2014.

[11] L. Hebbard and J. George, "Animal models of nonalcoholic fatty liver disease," Nature Reviews Gastroenterology and Hepatology, vol. 8, no. 1, pp. 34-44, 2011.

[12] Y. Takahashi, Y. Soejima, and T. Fukusato, "Animal models of nonalcoholic fatty liver disease/ nonalcoholic steatohepatitis," World Journal of Gastroenterology, vol. 18, no. 19, pp. 2300-2308, 2012.

[13] D. E. Kleiner, E. M. Brunt, M. Van Natta et al., "Design and validation of a histological scoring system for nonalcoholic fatty liver disease," Hepatology, vol. 41, no. 6, pp. 1313-1321, 2005.

[14] X. Sheng, M. Wang, M. Lu, B. Xi, H. Sheng, and Y. Q. Zang, "Rhein ameliorates fatty liver disease through negative energy balance, hepatic lipogenic regulation, and immunomodulation in diet-induced obese mice," The American Journal of Physiology -Endocrinology and Metabolism, vol. 300, no. 5, pp. E886-E893, 2011.

[15] J. Xiao, F. Xing, J. Huo et al., "Lycium barbarum polysaccharides therapeutically improve hepatic functions in non-alcoholic steatohepatitis rats and cellular steatosis model," Scientific Reports, vol. 4, article 5587, 2014.

[16] H. Zheng, J. Zhao, Y. Liu, Y. Zheng, J. Wu, and Z. Hong, "Effect of total alkaloids of Rubus alceaefolius on oxidative stress in rats with non-alcoholic fatty liver disease," Zhongguo Zhong Yao Za Zhi, vol. 36, no. 17, pp. 2383-2387, 2011.

[17] Y.-H. Jia, R.-Q. Wang, H.-M. Mi et al., "Fuzheng Huayu recipe prevents nutritional fibrosing steatohepatitis in mice," Lipids in Health and Disease, vol. 11, article 45, 2012.

[18] Z.-M. Mao, H.-Y. Song, L.-L. Yang et al., "Effects of the mixture of Swertia pseudochmensis Hara and Silybum marianum Gaertn extracts on $\mathrm{CCl}_{4}$-induced liver injury in rats with nonalcoholic fatty liver disease," Zhong Xi Yi Jie He Xue Bao, vol. 10, no. 2, pp. 193-199, 2012.

[19] Y.-Y. Wei, D. Yan, A. Japar, S.-S. Qu, A. A. Haji, and K. Parhat, "Effects of pomegranate flowers polyphenols on liver PON expression of diabetes combining non-alcoholic fat liver diseases rats," Yao Xue Xue Bao, vol. 48, no. 1, pp. 71-76, 2013.

[20] Y.-L. Ma, T. Li, B.-B. Wang et al., "Protection of huanglian jiedu decoction on livers of hyperlipidemia mice," Zhongguo Zhong Xi Yi Jie He Za Zhi, vol. 33, no. 8, pp. 1107-1111, 2013.

[21] Y. Takahashi, Y. Soejima, A. Kumagai, M. Watanabe, H. Uozaki, and T. Fukusato, "Inhibitory effects of Japanese herbal medicines sho-saiko-to and juzen-taiho-to on nonalcoholic steatohepatitis in mice," PLoS ONE, vol. 9, no. 1, Article ID e87279, 2014.

[22] X. Li, Y. Li, W. Yang et al., "SREBP-1c overexpression induces triglycerides accumulation through increasing lipid synthesis and decreasing lipid oxidation and VLDL assembly in bovine hepatocytes," Journal of Steroid Biochemistry and Molecular Biology, vol. 143, pp. 174-182, 2014.

[23] M. S. Shafiei, S. Shetty, P. E. Scherer, and D. C. Rockey, "Adiponectin regulation of stellate cell activation via PPARgamma-dependent and -independent mechanisms," The American Journal of Pathology, vol. 178, no. 6, pp. 26902699, 2011.

[24] M. Ono, M. Ogasawara, A. Hirose et al., "Bofutsushosan, a Japanese herbal (Kampo) medicine, attenuates progression of nonalcoholic steatohepatitis in mice," Journal of Gastroenterology, vol. 49, no. 6, pp. 1065-1073, 2014.

[25] S.-Y. Yang, N.-J. Zhao, X.-J. Li, H.-J. Zhang, K.-J. Chen, and C.-D. Li, "Ping-tang recipe improves insulin resistance and attenuates hepatic steatosis in high-fat diet-induced obese rats," Chinese Journal of Integrative Medicine, vol. 18, no. 4, pp. 262268, 2012.

[26] H. Hayashi and T. Sakai, "Animal models for the study of liver fibrosis: new insights from knockout mouse models," American Journal of Physiology-Gastrointestinal and Liver Physiology, vol. 300, no. 5, pp. G729-G738, 2011.

[27] C. Liedtke, T. Luedde, T. Sauerbruch et al., "Experimental liver fibrosis research: update on animal models, legal issues and translational aspects," Fibrogenesis and Tissue Repair, vol. 6, no. 1, article 19, 2013.

[28] R. G. Gieling, A. D. Burt, and D. A. Mann, "Fibrosis and cirrhosis reversibility-molecular mechanisms," Clinics in Liver Disease, vol. 12, no. 4, pp. 915-937, 2008.

[29] P. Starkel and I. A. Leclercq, "Animal models for the study of hepatic fibrosis," Best Practice and Research: Clinical Gastroenterology, vol. 25, no. 2, pp. 319-333, 2011.

[30] A. Baghdasaryan, P. Fickert, A. Fuchsbichler et al., "Role of hepatic phospholipids in development of liver injury in Mdr2 (Abcb4) knockout mice," Liver International, vol. 28, no. 7, pp. 948-958, 2008.

[31] S. Kanzler, A. W. Lohse, A. Keil et al., "TGF- $\beta 1$ in liver fibrosis: an inducible transgenic mouse model to study liver fibrogenesis," American Journal of Physiology-Gastrointestinal and Liver Physiology, vol. 276, no. 4, part 1, pp. G1059-G1068, 1999.

[32] Y.-N. Zhou, M.-Y. Sun, Y.-P. Mu et al., "Xuefuzhuyu decoction inhibition of angiogenesis attenuates liver fibrosis induced by $\mathrm{CCl}_{4}$ in mice," Journal of Ethnopharmacology, vol. 153, no. 3, pp. 659-666, 2014.

[33] X. Shen, S. Cheng, Y. Peng, H. Song, and H. Li, "Attenuation of early liver fibrosis by herbal compound 'Diwu Yanggan' through modulating the balance between epithelial-to-mesenchymal transition and mesenchymal-to-epithelial transition," BMC Complementary and Alternative Medicine, vol. 14, article 418, 2014.

[34] T.-F. Lee, Y.-L. Lin, and Y.-T. Huang, "Protective effects of kaerophyllin against liver fibrogenesis in rats," European Journal of Clinical Investigation, vol. 42, no. 6, pp. 607-616, 2012.

[35] Q.-L. Wang, Y.-Y. Tao, L. Shen, H.-Y. Cui, and C.-H. Liu, "Chinese herbal medicine Fuzheng Huayu recipe inhibits liver fibrosis by mediating the transforming growth factorbetal/Smads signaling pathway," Zhong Xi Yi Jie He Xue Bao, vol. 10, no. 5, pp. 561-568, 2012. 
[36] Y. Y. Tao, X. C. Yan, T. Zhou, L. Shen, Z. L. Liu, and C. H. Liu, "Fuzheng Huayu recipe alleviates hepatic fibrosis via inhibiting TNF- $\alpha$ induced hepatocyte apoptosis," BMC Complementary and Alternative Medicine, vol. 14, article 449, 2014.

[37] C. Luo, Z.-X. Chen, X.-H. Tan et al., "Therapeutic effects of Fuzhenghuayu decoction in a CCl4-induced liver cirrhosis rat model and on hepatic stellate cell activation," Zhonghua Gan Zang Bing Za Zhi, vol. 21, no. 9, pp. 668-673, 2013.

[38] L. Wang, X. Yan, Z. Zeng, J. Lv, P. Liu, and C. Liu, "Effect of fuzheng huayu recipe and huangqi tang on DMN-induced experimental liver cirrhosis in rats," Zhongguo Zhong Yao Za Zhi, vol. 35, no. 13, pp. 1740-1744, 2010.

[39] S. Dong, Q. L. Chen, and S. B. Su, "Curative effects of Fuzheng Huayu on liver fibrosis and cirrhosis: a meta-analysis," EvidenceBased Complementary and Alternative Medicine, vol. 2015, Article ID 125659, 11 pages, 2015.

[40] Y. Feng, N. Wang, X. Ye et al., "Hepatoprotective effect and its possible mechanism of Coptidis rhizoma aqueous extract on carbon tetrachloride-induced chronic liver hepatotoxicity in rats," Journal of Ethnopharmacology, vol. 138, no. 3, pp. 683-690, 2011.

[41] N. Wang, Y. Feng, F. Cheung et al., "A comparative study on the hepatoprotective action of bear bile and coptidis rhizoma aqueous extract on experimental liver fibrosis in rats," $B M C$ Complementary and Alternative Medicine, vol. 12, article 239, 2012.

[42] J.-X. Du, M.-Y. Sun, G.-L. Du et al., "Ingredients of Huangqi decoction slow biliary fibrosis progression by inhibiting the activation of the transforming growth factor-beta signaling pathway," BMC Complementary and Alternative Medicine, vol. 12, article 33, 2012.

[43] Y. Li, Z. Y. Tang, and J. X. Hou, "Hepatocellular carcinoma: insight from animal models," Nature Reviews Gastroenterology \& Hepatology, vol. 9, no. 1, pp. 32-43, 2012.

[44] L. Bakiri and E. F. Wagner, "Mouse models for liver cancer," Molecular Oncology, vol. 7, no. 2, pp. 206-223, 2013.

[45] T. Choedon, D. Dolma, and V. Kumar, "Pro-apoptotic and anticancer properties of Thapring - a Tibetan herbal formulation," Journal of Ethnopharmacology, vol. 137, no. 1, pp. 320-326, 2011.

[46] J. I. Johnson, S. Decker, D. Zaharevitz et al., "Relationships between drug activity in NCI preclinical in vitro and in vivo models and early clinical trials," British Journal of Cancer, vol. 84, no. 10, pp. 1424-1431, 2001.

[47] J. Zhang, X. Wang, and H. Lu, "Amifostine increases cure rate of cisplatin on ascites hepatoma 22 via selectively protecting renal thioredoxin reductase," Cancer Letters, vol. 260, no. 1-2, pp. 127136, 2008.

[48] G.-F. Ge, C.-H. Yu, B. Yu, Z.-H. Shen, D.-L. Zhang, and Q.-F. Wu, "Antitumor effects and chemical compositions of Eupolyphaga sinensis Walker ethanol extract," Journal of Ethnopharmacology, vol. 141, no. 1, pp. 178-182, 2012.

[49] Z.-Y. Cao, X.-Z. Chen, L.-M. Liao et al., "Fuzheng Yiliu Granule inhibits the growth of hepatocellular cancer by regulating immune function and inducing apoptosis in vivo and in vitro," Chinese Journal of Integrative Medicine, vol. 17, no. 9, pp. 691-697, 2011.

[50] M. You, M. Luo, W. Liao, S. Hu, W. Xu, and L. Jing, "Chaiqiyigan granula enhances Taxol-induced growth inhibition of hepatocellular carcinoma xenografts in nude mice: an in vivo fluorescence imaging study," Nan Fang Yi Ke Da Xue Xue Bao, vol. 32, no. 7, pp. 1042-1045, 2012.
[51] H. Y. Tan, N. Wang, S.-W. Tsao, Z. Zhang, and Y. Feng, "Suppression of vascular endothelial growth factor via inactivation of eukaryotic elongation factor 2 by alkaloids in Coptidis rhizome in hepatocellular carcinoma," Integrative Cancer Therapies, vol. 13, no. 5, pp. 425-434, 2014.

[52] N. Wang, Y. Feng, H. Y. Tan et al., "Inhibition of eukaryotic elongation factor-2 confers to tumor suppression by a herbal formulation Huanglian-Jiedu decoction in human hepatocellular carcinoma," Journal of Ethnopharmacology, vol. 164, pp. 309318, 2015.

[53] M. Wang, X. Zhang, X. Xiong et al., "Efficacy of the Chinese traditional medicinal herb Celastrus orbiculatus Thunb on human hepatocellular carcinoma in an orthothopic fluorescent nude mouse model," Anticancer Research, vol. 32, no. 4, pp. 12131220, 2012.

[54] C. M. Tsang, K. C. P. Cheung, Y. C. Cheung et al., "Berberine suppresses Id-1 expression and inhibits the growth and development of lung metastases in hepatocellular carcinoma," Biochimica et Biophysica Acta (BBA)-Molecular Basis of Disease, vol. 1852, no. 3, pp. 541-551, 2015.

[55] W. Bernal and J. Wendon, "Acute liver failure," The New England Journal of Medicine, vol. 369, no. 26, pp. 2525-2534, 2013.

[56] H. Z. Huo, B. Wang, Y. K. Liang, Y. Y. Bao, and Y. Gu, "Hepatoprotective and antioxidant effects of licorice extract against $\mathrm{CCl}_{4}$-induced oxidative damage in rats," International Journal of Molecular Sciences, vol. 12, no. 10, pp. 6529-6543, 2011.

[57] C.-Y. Teng, Y.-L. Lai, H.-I. Huang, W.-H. Hsu, C.-C. Yang, and W.-H. Kuo, "Tournefortia sarmentosa extract attenuates acetaminophen-induced hepatotoxicity," Pharmaceutical Biology, vol. 50, no. 3, pp. 291-396, 2012.

[58] K. Begriche, J. Massart, M.-A. Robin, F. Bonnet, and B. Fromenty, "Mitochondrial adaptations and dysfunctions in nonalcoholic fatty liver disease," Hepatology, vol. 58, no. 4, pp. 1497-1507, 2013.

[59] G. Gentric, V. Maillet, V. Paradis et al., "Oxidative stress promotes pathologic polyploidization in nonalcoholic fatty liver disease," The Journal of Clinical Investigation, vol. 125, no. 3, pp. 981-992, 2015.

[60] G. Poli, "Pathogenesis of liver fibrosis: role of oxidative stress," Molecular Aspects of Medicine, vol. 21, no. 3, pp. 49-98, 2000.

[61] M. Bhadauria, S. K. Nirala, and S. Shukla, "Propolis protects CYP 2E1 enzymatic activity and oxidative stress induced by carbon tetrachloride," Molecular and Cellular Biochemistry, vol. 302, no. 1-2, pp. 215-224, 2007.

[62] W. Li, Y. Li, Q. Wang, and Y. Yang, "Crude extracts from Lycium barbarum suppress SREBP-1c expression and prevent diet-induced fatty liver through AMPK activation," BioMed Research International, vol. 2014, Article ID 196198, 10 pages, 2014.

[63] S. Weber, O. A. Gressner, R. Hall, F. Grünhage, and F. Lammert, "Genetic determinants in hepatic fibrosis: from experimental models to fibrogenic gene signatures in humans," Clinics in Liver Disease, vol. 12, no. 4, pp. 747-757, 2008.

[64] Q. Xu, J. T. Norman, S. Shrivastav, J. Lucio-Cazana, and J. B. Kopp, "In vitro models of TGF- $\beta$-induced fibrosis suitable for high-throughput screening of antifibrotic agents," American Journal of Physiology-Renal Physiology, vol. 293, no. 2, pp. F631-F640, 2007.

[65] Q. Hu, M. Noor, Y. F. Wong et al., "In vitro anti-fibrotic activities of herbal compounds and herbs," Nephrology Dialysis Transplantation, vol. 24, no. 10, pp. 3033-3041, 2009. 
[66] C. Z. C. Chen, Y. X. Peng, Z. B. Wang et al., "The Scarin-a-Jar: studying potential antifibrotic compounds from the epigenetic to extracellular level in a single well," British Journal of Pharmacology, vol. 158, no. 5, pp. 1196-1209, 2009.

[67] Q. Tao, X.-N. Wang, Y.-P. Mu et al., "Dynamic change of lipid peroxidation-related protein expression and the intervention effects of Yiguanjian decoction in a rat model of CCl4-induced liver fibrosis," Zhonghua Gan Zang Bing Za Zhi, vol. 20, no. 2, pp. 116-121, 2012.

[68] X.-N. Wang, Q. Tao, Q. Feng, J.-H. Peng, P. Liu, and Y.-Y. $\mathrm{Hu}$, "Effects of Chinese herbal medicine Yiguanjian decoction on collagen metabolism of hepatic tissues in rats with $\mathrm{CCI}_{4}{ }^{-}$ induced liver fibrosis," Zhong Xi Yi Jie He Xue Bao, vol. 9, no. 6, pp. 651-657, 2011.

[69] X.-L. Wang, D.-W. Jia, H.-Y. Liu et al., "Effect of Yiguanjian decoction on cell differentiation and proliferation in $\mathrm{CCl}_{4}^{-}$ treated mice," World Journal of Gastroenterology, vol. 18, no. 25, pp. 3235-3249, 2012.

[70] W. Goessling and K. C. Sadler, "Zebrafish: an important tool for liver disease research," Gastroenterology, vol. 149, no. 6, pp. 13611377, 2015.

[71] Y. Asaoka, S. Terai, I. Sakaida, and H. Nishina, “The expanding role of fish models in understanding non-alcoholic fatty liver disease," Disease Models and Mechanisms, vol. 6, no. 4, pp. 905914, 2013.

[72] F. Miscevic, O. Rotstein, and X.-Y. Wen, "Advances in zebrafish high content and high throughput technologies," Combinatorial Chemistry and High Throughput Screening, vol. 15, no. 7, pp. 515$521,2012$.

[73] J. Tat, M. Liu, and X.-Y. Wen, "Zebrafish cancer and metastasis models for in vivo drug discovery," Drug Discovery Today: Technologies, vol. 10, no. 1, pp. e83-e89, 2013.

[74] G. K. Varshney and S. M. Burgess, "Mutagenesis and phenotyping resources in zebrafish for studying development and human disease," Briefings in Functional Genomics, vol. 13, no. 2, pp. 8294, 2014.

[75] V. Sapp, L. Gaffney, S. F. EauClaire, and R. P. Matthews, "Fructose leads to hepatic steatosis in zebrafish that is reversed by mechanistic target of rapamycin (mTOR) inhibition," Hepatology, vol. 60, no. 5, pp. 1581-1592, 2014.

[76] Q. Gu, X. Yang, L. Lin et al., "Genetic ablation of solute carrier family 7a3a leads to hepatic steatosis in zebrafish during fasting," Hepatology, vol. 60, no. 6, pp. 1929-1941, 2015.

[77] S. H. Kim, S. Y. Wu, J. I. Baek et al., "A post-developmental genetic screen for zebrafish models of inherited liver disease," PLoS ONE, vol. 10, no. 5, Article ID e0125980, 2015.

[78] K. Wang, L. Liu, W. Dai, X. Chen, X. Zheng, and J. Hou, "Establishment of a hepatic fibrosis model induced by diethylnitrosamine in zebrafish," Nan Fang Yi Ke Da Xue Xue Bao, vol. 34, no. 6, pp. 777-782, 2014.

[79] A. T. Nguyen, A. Emelyanov, C. H. V. Koh et al., "A high level of liver-specific expression of oncogenic Kras ${ }^{\mathrm{V} 12}$ drives robust liver tumorigenesis in transgenic zebrafish," Disease Models and Mechanisms, vol. 4, no. 6, pp. 801-813, 2011.

[80] A. T. Nguyen, A. Emelyanov, C. H. Koh, J. M. Spitsbergen, S. Parinov, and Z. Gong, "An inducible $\mathrm{Kras}^{\mathrm{V12}}$ transgenic zebrafish model for liver tumorigenesis and chemical drug screening," Disease Models \& Mechanisms, vol. 5, no. 1, pp. 63$72,2012$.

[81] Z. Li, W. Zheng, Z. Wang et al., "A transgenic zebrafish liver tumor model with inducible Myc expression reveals conserved
Myc signatures with mammalian liver tumors," Disease Models and Mechanisms, vol. 6, no. 2, pp. 414-423, 2013.

[82] L. Sun, A. T. Nguyen, J. M. Spitsbergen, and Z. Gong, "Mycinduced liver tumors in transgenic zebrafish can regress in tp53 null mutation," PLoS ONE, vol. 10, no. 1, Article ID e0117249, 2015.

[83] K. J. Evason, M. T. Francisco, V. Juric et al., "Identification of chemical inhibitors of $\beta$-catenin-driven liver tumorigenesis in zebrafish," PLoS Genetics, vol. 11, no. 7, Article ID e1005305, 2015.

[84] T. Liu, L.-L. Yang, L. Zhang, H.-Y. Song, D.-F. Li, and G. Ji, "Comparative study on the effects of different therapeutic methods in preventing and treating nonalcoholic fatty liver in rats," Zhong Xi Yi Jie He Xue Bao, vol. 10, no. 10, pp. 1120-1126, 2012.

[85] Z. Yao, X.-C. Liu, and Y.-E. Gu, "Schisandra chinensis Baill, a Chinese medicinal herb, alleviates high-fat-diet-inducing nonalcoholic steatohepatitis in rats," African Journal of Traditional, Complementary, and Alternative Medicines, vol. 11, no. 1, pp. 222-227, 2014.

[86] Q. Peng, Q. Zhang, W. Xiao et al., "Protective effects of Sapindus mukorossi Gaertn against fatty liver disease induced by high fat diet in rats," Biochemical and Biophysical Research Communications, vol. 450, no. 1, pp. 685-691, 2014.

[87] W. Tao, Z. Deqin, L. Yuhong et al., "Regulation effects on abnormal glucose and lipid metabolism of TZQ-F, a new kind of Traditional Chinese Medicine," Journal of Ethnopharmacology, vol. 128, no. 3, pp. 575-582, 2010.

[88] L.-L. Yang, M. Wang, T. Liu et al., "Effects of Chinese herbal medicine Jiangzhi granule on expressions of liver X receptor $\alpha$ and sterol regulatory element-binding protein-lc in a rat model of non-alcoholic fatty liver disease," Zhong Xi Yi Jie He Xue Bao, vol. 9, no. 9, pp. 998-1004, 2011.

[89] J. Liu, H. Zhang, B. Ji et al., "A diet formula of Puerariae radix, Lycium barbarum, Crataegus pinnatifida, and Polygonati rhizoma alleviates insulin resistance and hepatic steatosis in CD-1 mice and HepG2 cells," Food and Function, vol. 5, no. 5, pp. 1038-1049, 2014.

[90] S. Chen, H. Zhou, M. Lin, R. Mi, and L. Li, "Decoction vs extracts-mixed solution: effect of yiqihuoxue formula on non-alcoholic fatty liver disease in rats," Journal of Traditional Chinese Medicine, vol. 33, no. 4, pp. 513-517, 2013.

[91] Q.-H. Yang, S.-P. Hu, Y.-P. Zhang et al., "Effects of different therapeutic methods and typical recipes of Chinese medicine on activation of c-Jun $\mathrm{N}$-terminal kinase in Kupffer cells of rats with fatty liver disease," Chinese Journal of Integrative Medicine, vol. 18, no. 10, pp. 769-774, 2012.

[92] T.-Y. Lee, H.-H. Chang, W.-C. Lo, and H.-C. Lin, "Alleviation of hepatic oxidative stress by Chinese herbal medicine Yin-ChenHao-Tang in obese mice with steatosis," International Journal of Molecular Medicine, vol. 25, no. 6, pp. 837-844, 2010.

[93] Y.-J. Kim, M.-S. Choi, Y. B. Park, S. R. Kim, M.-K. Lee, and U. J. Jung, "Garcinia cambogia attenuates diet-induced adiposity but exacerbates hepatic collagen accumulation and inflammation," World Journal of Gastroenterology, vol. 19, no. 29, pp. 4689-4701, 2013.

[94] Q. Yang, Y. Xu, G. Feng et al., "p38 MAPK signal pathway involved in anti-inflammatory effect of Chaihu-Shugan-San and Shen-ling-bai-zhu-San on hepatocyte in non-alcoholic steatohepatitis rats," African Journal of Traditional, Complementary, and Alternative Medicines, vol. 11, no. 1, pp. 213-221, 2014.

[95] Q.-H. Yang, J. Huang, Y.-P. Zhang et al., "Effects of soothing liver and invigorating spleen recipes on the mRNA and protein 
expression of TLR4 in hepatic tissues of rats with NASH," Zhong Yao Cai, vol. 36, no. 1, pp. 78-84, 2013.

[96] Z.-F. Zhang, S.-H. Fan, Y.-L. Zheng et al., "Troxerutin improves hepatic lipid homeostasis by restoring $\mathrm{NAD}^{+}$depletion-mediated dysfunction of lipin 1 signaling in high-fat diet-treated mice," Biochemical Pharmacology, vol. 91, no. 1, pp. 74-86, 2014.

[97] L. Zhang, J. Xu, H. Song, Z. Yao, and G. Ji, "Extracts from SalviaNelumbinis naturalis alleviate hepatosteatosis via improving hepatic insulin sensitivity," Journal of Translational Medicine, vol. 12, no. 1, article 236, 2014.

[98] Y. Ma, J. Zhao, S. Yang, and Y. Jia, “Cigu Xiaozhi pills’s influence on lipid peroxidation and TNF- $\alpha$ expression in liver tissues of rats with nonalcoholic steatohepatitis," Zhongguo Zhong Yao Za Zhi, vol. 35, no. 10, pp. 1292-1297, 2010.

[99] H.-Y. Song, Z.-M. Mao, L.-L. Yang et al., "Dangfei liganning capsules attenuate the susceptibility of rat nonalcoholic fatty liver to carbon tetrachloride toxicity," Journal of Traditional Chinese Medicine, vol. 31, no. 4, pp. 327-333, 2011.

[100] Y.-J. Xu, Q.-H. Yang, L. Han et al., "Effects of soothing liver and invigorating spleen recipes on SREBP-1c, SCD-1 mRNA and proteins expression in hepatocytes of NAFLD rats," Zhong Yao Cai, vol. 37, no. 1, pp. 80-86, 2014.

[101] S. Takagi, T. Miura, E. Ishihara, T. Ishida, and Y. Chinzei, "Effect of corosolic acid on dietary hypercholesterolemia and hepatic steatosis in KK-Ay diabetic mice," Biomedical Research, vol. 31, no. 4, pp. 213-218, 2010.

[102] Y. Hirotani, A. Doi, T. Takahashi, H. Umezawa, Y. Urashima, and M. Myotoku, "Protective effects of the herbal medicine goshajinkigan in a rat model of non-alcoholic fatty liver disease," Biomedical Research, vol. 33, no. 6, pp. 373-376, 2012.

[103] Y. Xie, H.-P. Hao, H. Wang, Z.-X. Wang, and G.-J. Wang, "Reversing effects of silybin on TAA-induced hepatic CYP3A dysfunction through PXR regulation," Chinese Journal of Natural Medicines, vol. 11, no. 6, pp. 645-652, 2013.

[104] D. Abdulaziz Bardi, M. F. Halabi, N. A. Abdullah, E. Rouhollahi, M. Hajrezaie, and M. A. Abdulla, "In vivo evaluation of ethanolic extract of Zingiber officinale rhizomes for its protective effect against liver cirrhosis," BioMed Research International, vol. 2013, Article ID 918460, 10 pages, 2013.

[105] Y.-H. Paik, Y. J. Yoon, H. C. Lee et al., "Antifibrotic effects of magnesium lithospermate $\mathrm{B}$ on hepatic stellate cells and thioacetamide-induced cirrhotic rats," Experimental and Molecular Medicine, vol. 43, no. 6, pp. 341-349, 2011.

[106] K.-G. Kwak, J.-H. Wang, J.-W. Shin, D.-S. Lee, and C.-G. Son, "A traditional formula, Chunggan extract, attenuates thioacetamide-induced hepatofibrosis via GSH system in rats," Human \& Experimental Toxicology, vol. 30, no. 9, pp. 1322-1332, 2011.

[107] S.-C. Chien, W.-C. Chang, P.-H. Lin et al., "A Chinese herbal medicine, Jia-Wei-Xiao-Yao-San, prevents dimethylnitrosamine-induced hepatic fibrosis in rats," The Scientific World Journal, vol. 2014, Article ID 217525, 7 pages, 2014.

[108] C. Liu, P. Liu, and Q. Tao, "Recipe-syndrome correlation and pathogenesis mechanism of Yinchenhao Decoction in intervening dimethylnitrosamine induced liver cirrhosis progress in rats," Zhongguo Zhong Xi Yi Jie He Za Zhi, vol. 30, no. 8, pp. 845-850, 2010.

[109] C. Liu, G. Wang, G. Chen et al., "Huangqi decoction inhibits apoptosis and fibrosis, but promotes Kupffer cell activation in dimethylnitrosamine-induced rat liver fibrosis," BMC Complementary and Alternative Medicine, vol. 12, article 51, 2012.
[110] Y.-Q. Bian, B.-B. Ning, H.-Y. Cao et al., "Formula-syndrome correlation study of three classical anti-jaundice formulas in inhibition of liver fibrosis induced by dimethylnitrosamine in rats," Zhong Xi Yi Jie He Xue Bao, vol. 10, no. 12, pp. 1405-1412, 2012.

[111] X.-H. Tan, C.-Q. Li, S.-R. Zou et al., "Inhibitory effect of anluohuaxianwan on experimental hepatic fibrosis in rats," Zhonghua Gan Zang Bing Za Zhi, vol. 18, no. 1, pp. 9-12, 2010.

[112] X. Tong, G.-F. Chen, and Y. Lu, "Uniform designed research on the active ingredients assembling of huangqi decoction for inhibition of DMN-induced liver fibrosis," Zhongguo Zhong Xi Yi Jie He Za Zhi, vol. 31, no. 10, pp. 1389-1393, 2011.

[113] X. Zhang, B.-B. Ning, S. Ren et al., "Effects of Chinese herbal medicine Xiaopi Pill in preventing rats from dimethylnitrosamine-induced liver fibrosis," Zhong Xi Yi Jie He Xue Bao, vol. 10, no. 11, pp. 1286-1292, 2012.

[114] C.-G. Liu, X.-L. Wang, X.-W. Du et al., "Metabolomic profiling for identification of potential biomarkers in the protective effects of modified sinisan against liver injury in dimethylnitrosamine treated rats," Biological and Pharmaceutical Bulletin, vol. 36, no. 11, pp. 1700-1707, 2013.

[115] H.-J. Lin, J.-Y. Chen, C.-F. Lin et al., "Hepatoprotective effects of Yi Guan Jian, an herbal medicine, in rats with dimethylnitrosamine-induced liver fibrosis," Journal of Ethnopharmacology, vol. 134, no. 3, pp. 953-960, 2011.

[116] İ. Bingül, C. Başaran-Küçükgergin, M. S. Tekkeşin, V. Olgaç, S. Doğru-Abbasoğlu, and M. Uysal, "Effect of blueberry pretreatment on diethylnitrosamine-induced oxidative stress and liver injury in rats," Environmental Toxicology and Pharmacology, vol. 36, no. 2, pp. 529-538, 2013.

[117] R. Sferra, A. Vetuschi, V. Catitti et al., "Boswellia serrata and Salvia miltiorrhiza extracts reduce DMN-induced hepatic fibrosis in mice by TGF-betal downregulation," European Review for Medical and Pharmacological Sciences, vol. 16, no. 11, pp. 14841498, 2012.

[118] J.-Y. Chen, H.-L. Chen, J.-C. Cheng et al., "A Chinese herbal medicine, Gexia-Zhuyu Tang (GZT), prevents dimethylnitrosamine-induced liver fibrosis through inhibition of hepatic stellate cells proliferation," Journal of Ethnopharmacology, vol. 142, no. 3, pp. 811-818, 2012.

[119] Y. Qian, X.-C. Fu, R. Hu, L.-M. Shen, and H.-B. Bai, "Effects of Corbrin Shugan capsule on dimethylnitrosamine-induced hepatic fibrosis in rats," Zhejiang Da Xue Xue Bao Yi Xue Ban, vol. 42, no. 5, pp. 561-566, 2013.

[120] Z. Zhao, H. Yu, Y. Peng et al., "Comparison of effect of formulas clearing away heat and promoting blood circulation on prevention and treatment of liver fibrosis in CCl4 mice," Zhongguo Zhong Yao Za Zhi, vol. 37, no. 12, pp. 1804-1808, 2012.

[121] L. J. Zhang, M. Y. Sun, B. B. Ning et al., "Xiayuxue decoction ([symbols; see text]) attenuates hepatic stellate cell activation and sinusoidal endothelium defenestration in $\mathrm{CCl}_{4}$-induced fibrotic liver of mice," Chinese Journal of Integrative Medicine, vol. 20, no. 7, pp. 516-523, 2014.

[122] X.-X. Wu, L.-M. Wu, J.-J. Fan et al., "Cortex Dictamni extract induces apoptosis of activated hepatic stellate cells via STAT1 and attenuates liver fibrosis in mice," Journal of Ethnopharmacology, vol. 135, no. 1, pp. 173-178, 2011.

[123] H. Qiao, H. Han, D. Hong, Z. Ren, Y. Chen, and C. Zhou, "Protective effects of baicalin on carbon tetrachloride induced liver injury by activating PPAR $\gamma$ and inhibiting TGF $\beta 1$," Pharmaceutical Biology, vol. 49, no. 1, pp. 38-45, 2011. 
[124] G.-Y. Li, H.-Y. Gao, J. Huang, J. Lu, J.-K. Gu, and J.-H. Wang, "Hepatoprotective effect of Cichorium intybus L., a traditional Uighur medicine, against carbon tetrachloride-induced hepatic fibrosis in rats," World Journal of Gastroenterology, vol. 20, no. 16, pp. 4753-4760, 2014.

[125] X.-P. Tian, Y.-Y. Yin, and X. Li, "Effects and mechanisms of acremoniumterricola milleretal mycelium on liver fibrosis induced by carbon tetrachloride in rats," The American Journal of Chinese Medicine, vol. 39, no. 3, pp. 537-550, 2011.

[126] Z.-C. Wang, S. Yang, J.-J. Huang, S.-L. Chen, Q.-Q. Li, and Y. Li, "Effect of Rougan Huaqian granules combined with human mesenchymal stem cell transplantation on liver fibrosis in cirrhosis rats," Asian Pacific Journal of Tropical Medicine, vol. 7, no. 7, pp. 576-581, 2014.

[127] F.-R. Yang, B.-W. Fang, and J.-S. Lou, "Effects of Fufang Biejia Ruangan Pills on hepatic fibrosis in vivo and in vitro," World Journal of Gastroenterology, vol. 19, no. 32, pp. 5326-5333, 2013.

[128] C. Zhang, Y. Wang, H. Chen et al., "Protective effect of the herbal medicine Ganfukang against carbon tetrachloride induced liver fibrosis in rats," Molecular Medicine Reports, vol. 8, no. 3, pp. 954-962, 2013.

[129] W. Li, Y. Wu, C. Zhu, Z. Wang, R. Gao, and Q. Wu, "Anti-fibrosis effects of Huisheng oral solution in $\mathrm{CCl}_{4}$-induced hepatic fibrosis in rat," Indian Journal of Pharmacology, vol. 46, no. 2, pp. 216-221, 2014.

[130] A. N. B. Singab, N. A. Ayoub, E. N. Ali, and N. M. Mostafa, "Antioxidant and hepatoprotective activities of Egyptian moraceous plants against carbon tetrachloride-induced oxidative stress and liver damage in rats," Pharmaceutical Biology, vol. 48, no. 11, pp. 1255-1264, 2010.

[131] H. B. Cai, X. G. Sun, Z. F. Liu et al., "Effects of dahuangzhechong pills on cytokines and mitogen activated protein kinase activation in rats with hepatic fibrosis," Journal of Ethnopharmacology, vol. 132, no. 1, pp. 157-164, 2010.

[132] J.-X. Du, P. Liu, M.-Y. Sun et al., "Chinese herbal medicine Xiayuxue Decoction inhibits liver angiogenesis in rats with carbon tetrachloride-induced liver fibrosis," Zhong Xi Yi Jie He Xue Bao, vol. 9, no. 8, pp. 878-887, 2011.

[133] D.-Z. Shen, Q. Tao, J.-X. Du et al., "Effects of Yiguanjian Decoction on liver cirrhosis formation a differential proteomics study in rats," Zhong Xi Yi Jie He Xue Bao, vol. 8, no. 2, pp. 158$167,2010$.

[134] J.-C. Shu, L.-X. Chen, L. Deng et al., "Preliminary study on mechanism of therapeutic effect of Huganjiexian decoction on hepatic fibrosis," Zhonghua Gan Zang Bing Za Zhi, vol. 18, no. 3, pp. 189-193, 2010.

[135] Y.-P. Mu, X.-R. Chen, and Y.-F. Lu, "Effect of Xiaozheng Rongmu powder for the treatment of liver cirrhosis in rats," Zhongguo Zhong Xi Yi Jie He Za Zhi, vol. 30, no. 10, pp. 10781083, 2010.

[136] H. Jiang, J.-R. Gao, J.-F. Chen, and W.-B. Ji, "Effect of shuganjianpifang on the expression of BCL-2 and BAX in rats livers with hepatic fibrosis," Zhong Yao Cai, vol. 36, no. 5, pp. 776-780, 2013.

[137] D. W. Lim, Y. Lee, and Y. T. Kim, "Preventive effects of citrus unshiu peel extracts on bone and lipid metabolism in OVX rats," Molecules, vol. 19, no. 1, pp. 783-794, 2014.

[138] W.-Y. Sun, L. Wang, H. Liu, X. Li, and W. Wei, "A standardized extract from Paeonia lactiflora and Astragalus membranaceus attenuates liver fibrosis induced by porcine serum in rats," International Journal of Molecular Medicine, vol. 29, no. 3, pp. 491-498, 2012.
[139] X.-L. Liang and J.-Y. Yuan, "Effect of Chinese herbal compound on liver fibrosis in rabbits with schistosomiasis by Bultrasound," Asian Pacific Journal of Tropical Medicine, vol. 6, no. 8, pp. 658-662, 2013.

[140] P. Wang and Y.-Z. Liang, "Chemical composition and inhibitory effect on hepatic fibrosis of Danggui Buxue Decoction," Fitoterapia, vol. 81, no. 7, pp. 793-798, 2010.

[141] Y. Chen, Q. Chen, J. Lu, F.-H. Li, Y.-Y. Tao, and C.-H. Liu, "Effects of Danggui Buxue Decoction (fb) on lipid peroxidation and MMP-2/9 activities of fibrotic liver in rats," Chinese Journal of Integrative Medicine, vol. 15, no. 6, pp. 435-441, 2009.

[142] C. Huang, T. Ma, X. Meng et al., "Potential protective effects of a traditional Chinese herb, Litsea coreana Levl., on liver fibrosis in rats," Journal of Pharmacy and Pharmacology, vol. 62, no. 2, pp. 223-230, 2010.

[143] L.-J. Su, C.-C. Chang, C.-H. Yang et al., "Graptopetalum paraguayense ameliorates chemical-induced rat hepatic fibrosis in vivo and inactivates stellate cells and Kupffer cells in vitro," PLoS ONE, vol. 8, no. 1, Article ID e53988, 2013.

[144] T.-W. Kim, H.-K. Lee, I.-B. Song et al., "Protective effect of the aqueous extract from the root of Platycodon grandiflorum on cholestasis-induced hepatic injury in mice," Pharmaceutical Biology, vol. 50, no. 12, pp. 1473-1478, 2012.

[145] M. D. Yang, Y.-M. Chiang, R. Higashiyama et al., "Rosmarinic acid and baicalin epigenetically derepress peroxisomal proliferator-activated receptor $\gamma$ in hepatic stellate cells for their antifibrotic effect," Hepatology, vol. 55, no. 4, pp. 1271-1281, 2012.

[146] J.-M. Han, H.-G. Kim, M.-K. Choi et al., "Artemisia capillaris extract protects against bile duct ligation-induced liver fibrosis in rats," Experimental and Toxicologic Pathology, vol. 65, no. 6, pp. 837-844, 2013.

[147] S.-J. Hsu, S.-S. Wang, I.-F. Hsin et al., "Green tea polyphenol decreases the severity of portosystemic collaterals and mesenteric angiogenesis in rats with liver cirrhosis," Clinical Science, vol. 126, no. 9, pp. 633-644, 2014.

[148] J.-X. Du, B.-F. Qiu, P. Liu, M.-Y. Sun, G.-F. Chen, and J. Liu, "Huangqi decoction inhibits cholangiocyte proliferation and transdifferentiation in cholestatic liver fibrosis induced by BDL in rats," Zhonghua Gan Zang Bing Za Zhi, vol. 18, no. 1, pp. 13-18, 2010.

[149] T. Asakawa, M. Yagi, Y. Tanaka et al., "The herbal medicine Inchinko-to reduces hepatic fibrosis in cholestatic rats," Pediatric Surgery International, vol. 28, no. 4, pp. 379-384, 2012.

[150] Z. Cao, L. Liao, X. Chen et al., "Enhancement of antitumor activity of low-dose 5-fluorouracil by combination with FuzhengYiliu granules in hepatoma 22 tumor-bearing mice," Integrative Cancer Therapies, vol. 12, no. 2, pp. 174-181, 2013.

[151] X. Q. Song, Y. L. Guo, B. G. Wang, S. J. Sun, and R. Y. Yao, "Effect of tagalsin on p53 and Bcl-2 expression in hepatoma $\mathrm{H}(22)$ tumor-bearing mice," Zhonghua Zhong Liu Za Zhi, vol. 33, no. 7, pp. 499-503, 2011.

[152] J. Chen, X. Jin, J. Chen, and C. Liu, "Glycyrrhiza polysaccharide induces apoptosis and inhibits proliferation of human hepatocellular carcinoma cells by blocking PI3K/AKT signal pathway," Tumor Biology, vol. 34, no. 3, pp. 1381-1389, 2013.

[153] A. Wei, D. Zhou, J. Ruan, Y. Cai, C. Xiong, and G. Wu, "Anti-tumor and anti-angiogenic effects of Macrothelypteris viridifrons and its constituents by HPLC-DAD/MS analysis," Journal of Ethnopharmacology, vol. 139, no. 2, pp. 373-380, 2012.

[154] Z. Cao, W. Lin, Z. Huang et al., "Ethyl acetate extraction from a Chinese herbal formula, Jiedu Xiaozheng Yin, inhibits the 
proliferation of hepatocellular carcinoma cells via induction of G0/G1 phase arrest in vivo and in vitro," International Journal of Oncology, vol. 42, no. 1, pp. 202-210, 2013.

[155] L.-R. Zhang, Y. Tang, and G.-R. Jiang, "The protection of yupingfeng powder on cisplatin induced oxidative damage of organs in hepatocellular carcinoma mice," Zhongguo Zhong Xi Yi Jie He Za Zhi, vol. 32, no. 5, pp. 647-651, 2012.

[156] X. He, X. Li, B. Liu, L. Xu, H. Zhao, and A. Lu, "Down-regulation of Treg cells and up-regulation of TH1/TH2 cytokine ratio were induced by polysaccharide from Radix Glycyrrhizae in H22 hepatocarcinoma bearing mice," Molecules, vol. 16, no. 10, pp. 8343-8352, 2011.

[157] Y. He, J. Wang, X. Liu et al., "Toosendanin inhibits hepatocellular carcinoma cells by inducing mitochondria-dependent apoptosis," Planta Medica, vol. 76, no. 13, pp. 1447-1453, 2010.

[158] L. Ji, K. Shen, P. Jiang, G. Morahan, and Z. Wang, "Critical roles of cellular glutathione homeostasis and jnk activation in andrographolide-mediated apoptotic cell death in human hepatoma cells," Molecular Carcinogenesis, vol. 50, no. 8, pp. 580-591, 2011.

[159] J.-M. Wang, L.-L. Ji, C. J. Banford-White et al., "Antitumor activity of Dioscorea bulbifera L. rhizome in vivo," Fitoterapia, vol. 83, no. 2, pp. 388-394, 2012.

[160] S.-X. Zhang, C. Zhu, Y. Ba et al., "Gekko-sulfated glycopeptide inhibits tumor angiogenesis by targeting basic fibroblast growth factor," The Journal of Biological Chemistry, vol. 287, no. 16, pp. 13206-13215, 2012.

[161] Y.-S. Chen, Y. He, C. Chen et al., "Growth inhibition by pennogenyl saponins from Rhizoma paridis on hepatoma xenografts in nude mice," Steroids, vol. 83, pp. 39-44, 2014.

[162] S.-H. Fan, Y.-Y. Wang, J. Lu et al., "Luteoloside suppresses proliferation and metastasis of hepatocellular carcinoma cells by inhibition of NLRP3 inflammasome," PLoS ONE, vol. 9, no. 2, Article ID e89961, 2014.

[163] Y. Ming, Z. Zheng, L. Chen et al., "Corilagin inhibits hepatocellular carcinoma cell proliferation by inducing G2/M phase arrest," Cell Biology International, vol. 37, no. 10, pp. 1046-1054, 2013.

[164] X.-Z. Chen, Z.-Y. Cao, T.-S. Chen et al., "Water extract of Hedyotis Diffusa Willd suppresses proliferation of human HepG2 cells and potentiates the anticancer efficacy of low-dose 5-fluorouracil by inhibiting the CDK2-E2F1 pathway," Oncology Reports, vol. 28, no. 2, pp. 742-748, 2012.

[165] X.-Z. Chen, Z.-Y. Cao, J.-N. Li et al., "Ethyl acetate extract from Jiedu Xiaozheng Yin inhibits the proliferation of human hepatocellular carcinoma cells by suppressing polycomb gene product Bmil and Wnt/ $\beta$-catenin signaling," Oncology Reports, vol. 32, no. 6, pp. 2710-2718, 2014.

[166] Y. Li and S. Hu, "Triptolide sensitizes liver cancer cell lines to chemotherapy in vitro and in vivo," Panminerva Medica, vol. 56, no. 3, pp. 211-220, 2014.

[167] Y.-L. Li, B.-G. Sun, T. Xiang, Z.-X. Chen, and S.-J. Zhang, "Effect of invigorating spleen and detoxification decoction on MHC I/MHC II in spleen-deficiency liver cancer rats survival," Zhong Yao Cai, vol. 37, no. 3, pp. 454-460, 2014.

[168] W. Lin, J. Zhao, Z. Cao et al., "Livistona chinensis seeds inhibit hepatocellular carcinoma angiogenesis in vivo via suppression of the Notch pathway," Oncology Reports, vol. 31, no. 4, pp. 17231728, 2014.

[169] H. Ma, B. Liu, D. Feng et al., "Pinus massoniana bark extract selectively induces apoptosis in human hepatoma cells, possibly through caspase-dependent pathways," International Journal of Molecular Medicine, vol. 25, no. 5, pp. 751-759, 2010.

[170] S.-J. Wang, A.-L. Wei, and Y.-Q. Zhang, "Aitongxiao recipe regulated survivin and $\mathrm{Bcl}-2$ in rats' transplanted hepatoma carcinoma cell," Zhongguo Zhong Xi Yi Jie He Za Zhi, vol. 32, no. 12, pp. 1652-1657, 2012.

[171] M.-H. Wu and L. Li, "Effect of xiaoai jiedu recipe on gene expression profiles in $\mathrm{H} 22$ tumor-bearing mice," Zhongguo Zhong Xi Yi Jie He Za Zhi, vol. 33, no. 9, pp. 1232-1235, 2013.

[172] P.-F. Wu, H.-C. Tseng, C.-C. Chyau, J.-H. Chen, and F.-P. Chou, "Piper betle leaf extracts induced human hepatocellular carcinoma Hep3B cell death via MAPKs regulating the p73 pathway in vitro and in vivo," Food and Function, vol. 5, no. 12, pp. 3320-3328, 2014.

[173] S. Xi, R. Hong, J. Huang et al., "Effects of Ciji Hua'ai Baosheng Granule Formula (CHBGF) on life time, pathology, peripheral blood cells of tumor chemotherapymodelmouse with $\mathrm{H}_{22}$ hepatoma carcinomacells," African Journal of Traditional, Complementary and Alternative Medicines, vol. 11, no. 4, pp. 94-100, 2014.

[174] G.-M. Yang, R. Yan, Z.-X. Wang, F.-F. Zhang, Y. Pan, and B.-C. Cai, "Antitumor effects of two extracts from Oxytropis falcata on hepatocellular carcinoma in vitro and in vivo," Chinese Journal of Natural Medicines, vol. 11, no. 5, pp. 519-524, 2013.

[175] J. Yang, X. Li, Y. Xue, N. Wang, and W. Liu, "Anti-hepatoma activity and mechanism of corn silk polysaccharides in H22 tumor-bearing mice," International Journal of Biological Macromolecules, vol. 64, pp. 276-280, 2014.

[176] Y. Zhong, C.-L. Luo, and Z. An-Jun, "Effect of bushen jianpi decoction and its disassemble recipes on tumor growth in mice with transplanted primary hepatic carcinoma," Zhongguo Zhong Xi Yi Jie He Za Zhi, vol. 31, no. 2, pp. 213-217, 2011.

[177] K. Chen, S. Zhang, Y. Ji et al., "Baicalein inhibits the invasion and metastatic capabilities of hepatocellular carcinoma cells via down-regulation of the ERK pathway," PLoS ONE, vol. 8, no. 9, Article ID e72927, 2013.

[178] B. Sun, J. Meng, T. Xiang et al., "Jianpijiedu Fang improved survival of hepatocarcinoma mice by affecting phosphatase and tensin homolog, phosphoinositide 3-kinase, and focal adhesion kinase," Journal of Traditional Chinese Medicine, vol. 33, no. 4, pp. 479-485, 2013.

[179] W. Xiong, Z.-Y. Tang, Z.-G. Ren et al., "Effects of the Chinese herbal extract Songyou Yin on the residual hepatocellular carcinoma after chemotherapy in nude mice," Zhonghua Zhong Liu Za Zhi, vol. 35, no. 11, pp. 804-807, 2013.

[180] X.-Q. Liu, X.-J. Hu, H.-X. Xu, and X.-Y. Zeng, "Xiaochaihu Decoction attenuates the vicious circle between the oxidative stress and the ALP inactivation through LPS-catecholamines interactions in gut, liver and brain during CCI4+ethanolinduced mouse HCC," BMC Complementary and Alternative Medicine, vol. 13, article 375, 2013.

[181] S. Verma, T. Bahorun, R. K. Singh, O. I. Aruoma, and A. Kumar, "Effect of Aegle marmelos leaf extract on N-methyl $\mathrm{N}$-nitrosourea-induced hepatocarcinogensis in Balb/c mice," Pharmaceutical Biology, vol. 51, no. 10, pp. 1272-1281, 2013.

[182] Y. Lei, A.-M. Zhou, T. Guo, Y. Tan, Y.-Y. Tao, and C.-H. Liu, "Protective effect of Tanreqing injection on acute hepatic injury induced by CCl4 in rats," Zhongguo Zhong Yao Za Zhi, vol. 38, no. 8, pp. 1226-1230, 2013. 
[183] J. Xiao, E. C. Liong, Y. P. Ching et al., "Lycium barbarum polysaccharides protect mice liver from carbon tetrachlorideinduced oxidative stress and necroinflammation," Journal of Ethnopharmacology, vol. 139, no. 2, pp. 462-470, 2012.

[184] T.-Y. Lai, Y.-J. Weng, W.-W. Kuo et al., “Taohe Chengqi Tang ameliorates acute liver injury induced by carbon tetrachloride in rats," Zhong Xi Yi Jie He Xue Bao, vol. 8, no. 1, pp. 49-55, 2010.

[185] V. N. Shah, M. B. Shah, and P. A. Bhatt, "Hepatoprotective activity of punarnavashtak kwath, an Ayurvedic formulation, against CCl4-induced hepatotoxicity in rats and on the HepG2 cell line," Pharmaceutical Biology, vol. 49, no. 4, pp. 408-415, 2011.

[186] A. K. Shakya, M. Saxena, N. Sharma, S. Shrivastava, and S. Shukla, "Hepatoprotective efficacy of sharbat-e-deenar against carbon tetrachloride-induced liver damage," Journal of Environmental Pathology, Toxicology and Oncology, vol. 31, no. 2, pp. 131-141, 2012.

[187] A. K. Shakya, N. Sharma, M. Saxena, S. Shrivastava, and S. Shukla, "Evaluation of the antioxidant and hepatoprotective effect of Majoon-e-Dabeed-ul-ward against carbon tetrachloride induced liver injury," Experimental and Toxicologic Pathology, vol. 64, no. 7-8, pp. 767-773, 2012.

[188] S. Umer, K. Asres, and C. Veeresham, "Hepatoprotective activities of two Ethiopian medicinal plants," Pharmaceutical Biology, vol. 48, no. 4, pp. 461-468, 2010.

[189] H. Zhang, C.-H. Yu, Y.-P. Jiang et al., "Protective effects of polydatin from Polygonum cuspidatum against carbon tetrachloride-induced liver injury in mice," PLOS ONE, vol. 7, no. 9, Article ID e46574, 2012.

[190] G. Zhou, Y. Chen, S. Liu, X. Yao, and Y. Wang, "In vitro and in vivo hepatoprotective and antioxidant activity of ethanolic extract from Meconopsis integrifolia (Maxim.) Franch," Journal of Ethnopharmacology, vol. 148, no. 2, pp. 664-670, 2013.

[191] G. Ai, Q. Liu, W. Hua, Z. Huang, and D. Wang, "Hepatoprotective evaluation of the total flavonoids extracted from flowers of Abelmoschus manihot (L.) Medic: in vitro and in vivo studies," Journal of Ethnopharmacology, vol. 146, no. 3, pp. 794-802, 2013.

[192] G. Cao, Q. Li, X. Chen, H. Cai, and S. Tu, "Hepatoprotective effect of superfine particles of herbal medicine against $\mathrm{CCl}_{4}$ induced acute liver damage in rats," BioMed Research International, vol. 2014, Article ID 934732, 6 pages, 2014.

[193] M. A. Esmaeili and M. Alilou, "Naringenin attenuates $\mathrm{CCl}_{4}$ induced hepatic inflammation by the activation of an Nrf2mediated pathway in rats," Clinical and Experimental Pharmacology and Physiology, vol. 41, no. 6, pp. 416-422, 2014.

[194] R. M. P. Gutierrez, I. A. Sosa, C. H. Vadillo, and T. C. Victoria, "Effect of flavonoids from Prosthechea michuacana on carbon tetrachloride induced acute hepatotoxicity in mice," Pharmaceutical Biology, vol. 49, no. 11, pp. 1121-1127, 2011.

[195] M. R. Islam, M. S. Parvin, and M. E. Islam, "Antioxidant and hepatoprotective activity of an ethanol extract of Syzygium jambos (L.) leaves," Drug Discoveries \& Therapeutics, vol. 6, no. 4, pp. 205-211, 2012.

[196] P. Wang, Y. Zhang, Y. An et al., "Protection of a new heptapeptide from carapax trionycis against carbon tetrachlorideinduced acute liver injury in mice," Chemical and Pharmaceutical Bulletin, vol. 61, no. 11, pp. 1130-1135, 2013.

[197] S. Alqasoumi, "Carbon tetrachloride-induced hepatotoxicity: protective effect of 'Rocket' Eruca sativa L. in rats," American Journal of Chinese Medicine, vol. 38, no. 1, pp. 75-88, 2010.

[198] A. B. Saba, O. M. Onakoya, and A. A. Oyagbemi, "Hepatoprotective and in vivo antioxidant activities of ethanolic extract of whole fruit of Lagenaria breviflora," Journal of Basic and Clinical Physiology and Pharmacology, vol. 23, no. 1, pp. 27-32, 2012.

[199] C.-C. Tian, X.-Q. Zha, L.-H. Pan, and J.-P. Luo, "Structural characterization and antioxidant activity of a low-molecular polysaccharide from Dendrobium huoshanense," Fitoterapia, vol. 91, pp. 247-255, 2013.

[200] Y. Chen, Y. Miao, L. Huang et al., "Antioxidant activities of saponins extracted from Radix Trichosanthis: an in vivo and in vitro evaluation," BMC Complementary and Alternative Medicine, vol. 14, article 86, 2014.

[201] M. S. Al-Said, R. A. Mothana, M. O. Al-Sohaibani, and S. Rafatullah, "Ameliorative effect of Grewia tenax (Forssk) fiori fruit extract on $\mathrm{CCl}_{4}$-induced oxidative stress and hepatotoxicity in rats," Journal of Food Science, vol. 76, no. 9, pp. T200-T206, 2011.

[202] J. H. Donfack, C. C. F. Simo, B. Ngameni et al., "Antihepatotoxic and antioxidant activities of methanol extract and isolated compounds from Ficus chlamydocarpa," Natural Product Communications, vol. 5, no. 10, pp. 1607-1612, 2010.

[203] S. E. El-Gengaihi, M. A. Hamed, A. E.-R. M. Khalaf-Allah, and M. A. Mohammed, "Golden berry juice attenuates the severity of hepatorenal injury," Journal of Dietary Supplements, vol. 10, no. 4, pp. 357-369, 2013.

[204] J. Song, J. Zhao, X. Wang, Y. Dai, Z. Deng, and J. Yi, “Protective effects of Shaoganduogan on hepatocyte mitochondria in subacute liver injury rat induced by carbon tetrachloride," Zhongguo Zhong Yao Za Zhi, vol. 36, no. 7, pp. 931-934, 2011.

[205] Y.-X. Zhou, Y.-Q. Qiu, L.-Q. Xu, J. Guo, and L.-J. Li, "Xiao-Chai$\mathrm{Hu}$ Tang in treating model mice with $\mathrm{D}$-galactosamine-induced liver injury," African Journal of Traditional, Complementary and Alternative Medicines, vol. 9, no. 3, pp. 405-411, 2012.

[206] S. Banu, B. Bhaskar, and P. Balasekar, "Hepatoprotective and antioxidant activity of Leucas aspera against D-galactosamine induced liver damage in rats," Pharmaceutical Biology, vol. 50, no. 12, pp. 1592-1595, 2012.

[207] R. Rajamurugan, A. Suyavaran, N. Selvaganabathy et al., "Brassica nigra plays a remedy role in hepatic and renal damage," Pharmaceutical Biology, vol. 50, no. 12, pp. 1488-1497, 2012.

[208] Z.-Q. Jiang, Y. Li, L.-H. Jiang, H. Gu, and M.-Y. Wang, "Hepatoprotective effects of extracts from processed corni fructus against D-galactose-induced liver injury in mice," Zhong Yao Cai, vol. 36, no. 1, pp. 85-89, 2013.

[209] S. Zhang, D. Wang, X. Wang et al., "Aqueous extract of BaiHu-Tang, a classical Chinese herb formula, prevents excessive immune response and liver injury induced by LPS in rabbits," Journal of Ethnopharmacology, vol. 149, no. 1, pp. 321-327, 2013.

[210] X. Li, C. Gou, H. Yang, J. Qiu, T. Gu, and T. Wen, "Echinacoside ameliorates D-galactosamine plus lipopolysaccharide-induced acute liver injury in mice via inhibition of apoptosis and inflammation," Scandinavian Journal of Gastroenterology, vol. 49, no. 8, pp. 993-1000, 2014.

[211] J.-L. Zhang, H. Zeng, and X.-B. Wang, "Discussion of Chinese syndrome typing in acute hepatic failure model," Zhongguo Zhong Xi Yi Jie He Za Zhi, vol. 31, no. 5, pp. 659-662, 2011.

[212] Y.-G. Yang, Y.-W. Liu, H.-Y. Hua, and L.-J. Li, "Effect of Sanhuangyinchi decoction on liver damage and caspase-3 in rats with acute hepatic failure," Nan Fang Yi Ke Da Xue Xue Bao, vol. 30, no. 11, pp. 2443-2445, 2010.

[213] T. Zhou, X.-C. Yan, Q. Chen et al., "Effects of Chinese herbal medicine Fuzheng Huayu recipe and its components against hepatocyte apoptosis in mice with hepatic injury," Zhong Xi Yi Jie He Xue Bao, vol. 9, no. 1, pp. 57-63, 2011. 
[214] W. Ma, Y. Yang, J. Diao, Y. Liu, H. Hua, and X. Wen, "Sanhuangyinchi decoction pretreatment ameliorates acute hepatic failure in rats by suppressing antioxidant stress and caspase-3 expression," Nan Fang Yi Ke Da Xue Xue Bao, vol. 34, no. 4, pp. 482-486, 2014.

[215] F.-L. Wang, H.-Z. Yang, Y.-M. Li, W.-K. Wu, and Z.-C. Zou, "Prevention and treatment mechanism of qingxia therapy (based on yinchenhao decoction and dachengqi decoction) on hepatocyte apoptosis in rats with acute hepatic injury induced by lipopolysaccharide/D-galactosamine," Zhong Yao Cai, vol. 37, no. 5, pp. 848-852, 2014.

[216] R. Nagalekshmi, A. Menon, D. K. Chandrasekharan, and C. K. K. Nair, "Hepatoprotective activity of Andrographis paniculata and Swertia chirayita," Food and Chemical Toxicology, vol. 49, no. 12, pp. 3367-3373, 2011.

[217] D. S. Kushwah, M. T. Salman, P. Singh, V. K. Verma, and A. Ahmad, "Protective effects of ethanolic extract of Nigella sativa seed in paracetamol induced acute hepatotoxicity In vivo," Pakistan Journal of Biological Sciences, vol. 17, no. 4, pp. 517-522, 2014.

[218] V. Madhavan, A. S. Pandey, A. Murali, and S. N. Yoganarasimhan, "Protective effects of Capparis sepiaria root extracts against acetaminophen-induced hepatotoxicity in Wistar rats," Journal of Complementary \& Integrative Medicine, vol. 9, article 1, 2012.

[219] N. Anusuya, K. Raju, and S. Manian, "Hepatoprotective and toxicological assessment of an ethnomedicinal plant Euphorbia fusiformis Buch.-Ham.ex D.Don," Journal of Ethnopharmacology, vol. 127, no. 2, pp. 463-467, 2010.

[220] A. J. S. J. Samuel, S. Mohan, D. K. Chellappan, A. Kalusalingam, and S. Ariamuthu, "Hibiscus vitifolius (Linn.) root extracts shows potent protective action against anti-tubercular drug induced hepatotoxicity," Journal of Ethnopharmacology, vol. 141, no. 1, pp. 396-402, 2012.

[221] M. A. Gbadegesin and O. A. Odunola, "Aqueous and ethanolic leaf extracts of Ocimum basilicum (sweet basil) protect against sodium arsenite-induced hepatotoxicity in Wistar rats," Nigerian Journal of Physiological Sciences, vol. 25, no. 1, pp. 29-36, 2010.

[222] H. G. Kim, J. S. Lee, J. S. Lee, J. M. Han, and C. G. Son, "Hepatoprotective and antioxidant effects of Myelophil on restraint stress-induced liver injury in BALB/c mice," Journal of Ethnopharmacology, vol. 142, no. 1, pp. 113-120, 2012.

[223] Y. S. Al-Awthan, S. M. Hezabr, A. M. Al-Zubairi, and F. A. Al-Hemiri, "Effects of aqueous extract of Withania somnifera on some liver biochemical and histopathological parameters in male guinea pigs," Pakistan Journal of Biological Sciences, vol. 17, no. 4, pp. 504-510, 2014.

[224] S. Matić, S. Stanić, D. Bogojević et al., "Methanol extract from the stem of Cotinus coggygria Scop., and its major bioactive phytochemical constituent myricetin modulate pyrogallol-induced DNA damage and liver injury," Mutation Research/Genetic Toxicology and Environmental Mutagenesis, vol. 755, no. 2, pp. 81-89, 2013.

[225] S. Ravikumar, M. Gnanadesigan, S. Jacob Inbaneson, and A. Kalaiarasi, "Hepatoprotective and antioxidant properties of Suaeda maritima (L.) Dumort ethanolic extract on concanavalin-A induced hepatotoxicity in rats," Indian Journal of Experimental Biology, vol. 49, no. 6, pp. 455-460, 2011.

[226] K. Vijayavel, C. Anbuselvam, and B. Ashokkumar, "Protective effect of Coleus aromaticus Benth (Lamiaceae) against naphthalene-induced hepatotoxicity," Biomedical and Environmental Sciences, vol. 26, no. 4, pp. 295-302, 2013.

[227] T. Wu, M.-J. Chang, Y.-J. Xu, X.-P. Li, G. Du, and D. Liu, "Protective effect of Calculus bovis sativus on intrahepatic cholestasis in rats induced by alpha-naphthylisothiocyanate," The American Journal of Chinese Medicine, vol. 41, no. 6, pp. 1393-1405, 2013.

[228] L.-L. Ding, B.-F. Zhang, W. Dou, L. Yang, C.-S. Zhan, and Z.-T. Wang, "Protective effect of Danning tablet on acute livery injury with cholestasis induced by $\alpha$-naphthylisothiocyanate in rats," Journal of Ethnopharmacology, vol. 140, no. 2, pp. 222-229, 2012. 


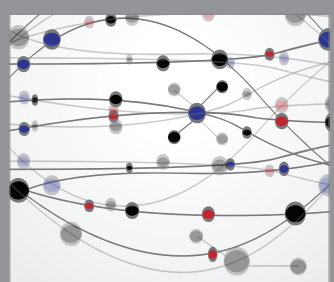

The Scientific World Journal
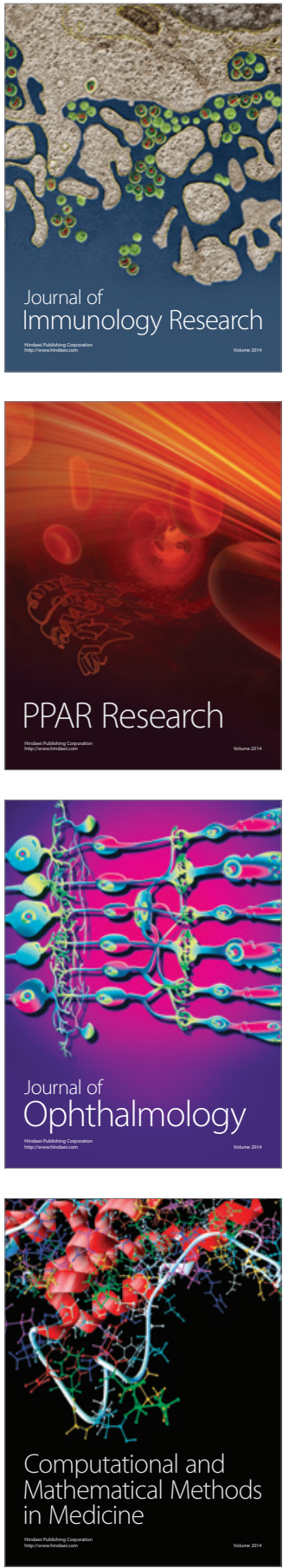

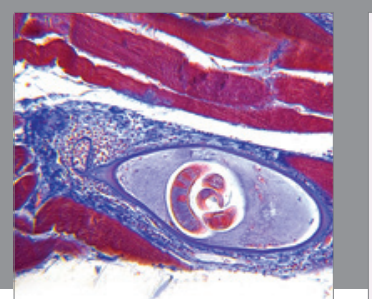

Gastroenterology Research and Practice

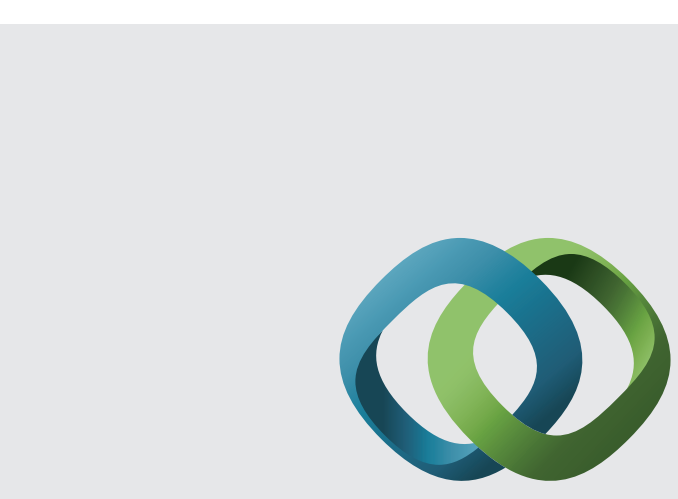

\section{Hindawi}

Submit your manuscripts at

http://www.hindawi.com
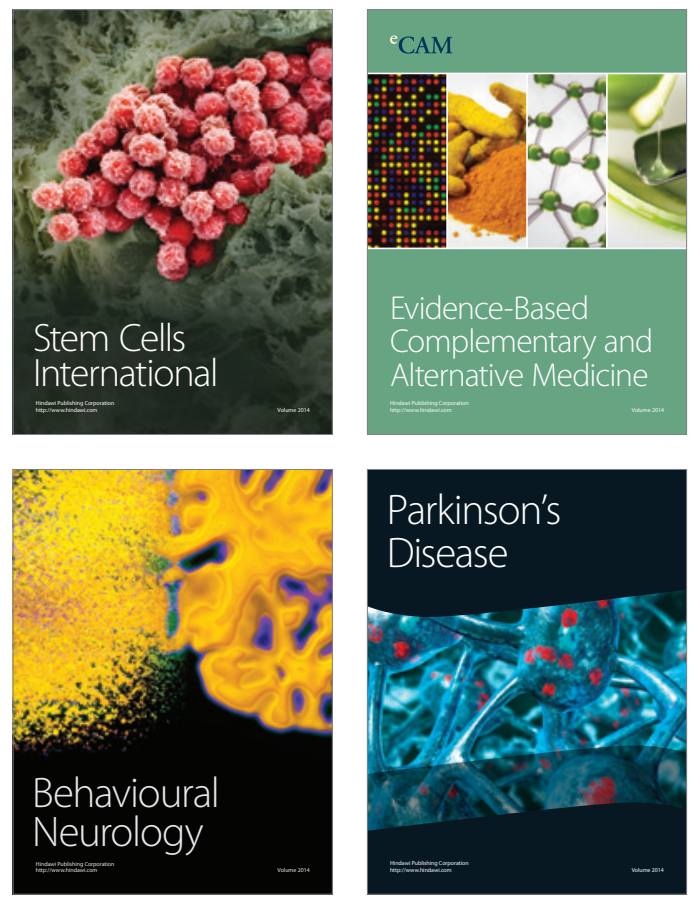
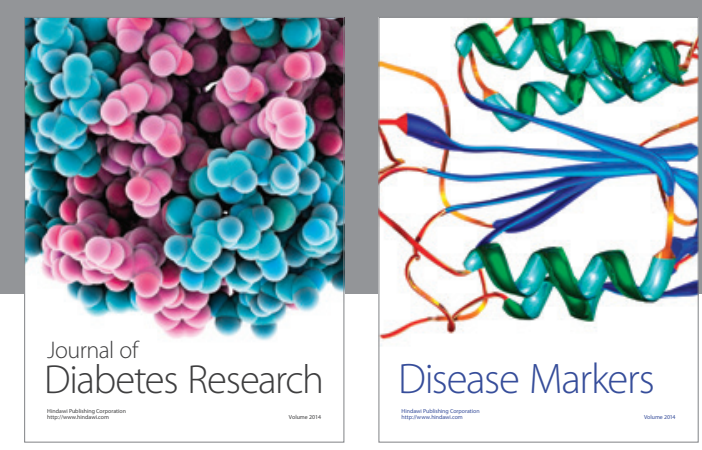

Disease Markers
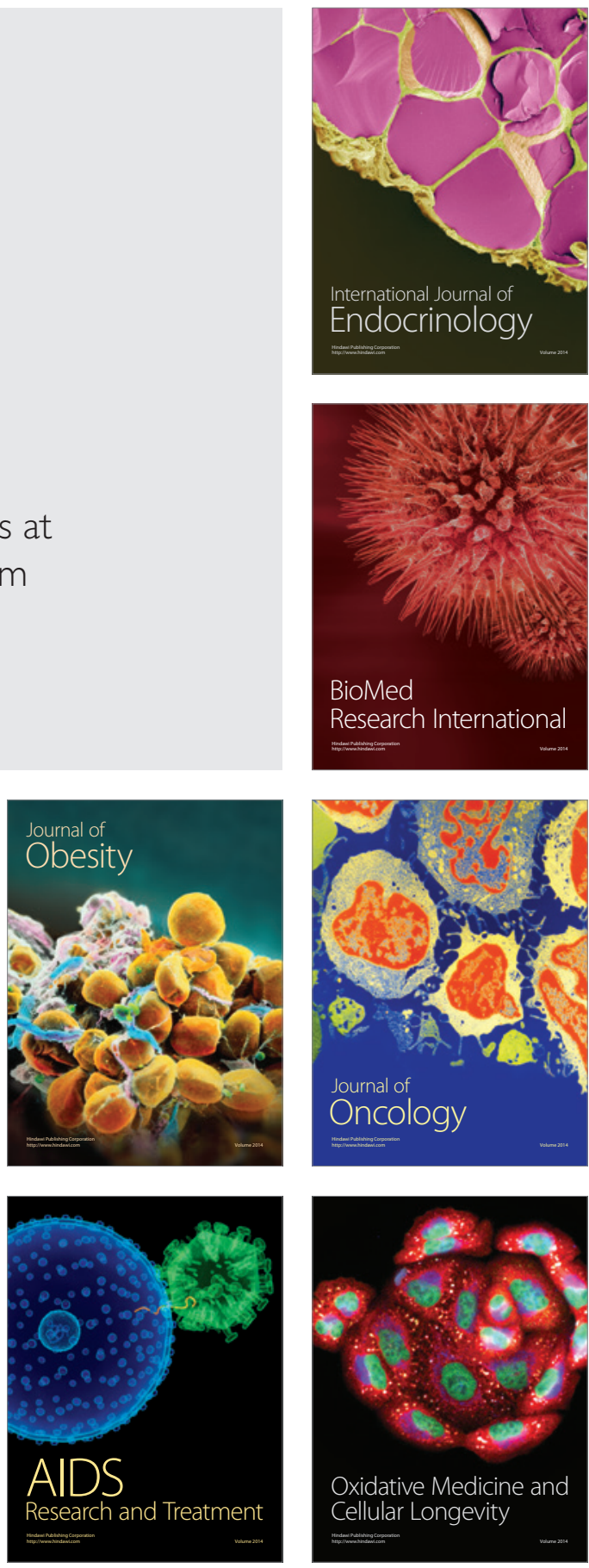